\title{
Reactivity of 3-nitroindoles with electron-rich species
}

Received 00th January 20xx, Accepted 00th January 20xx

DOI: $10.1039 / x 0 \times x 00000 x$
Batoul Rkein, ${ }^{a}$ Antoine Bigot, ${ }^{a}$ Léo Birbaum, ${ }^{a}$ Maxime Manneveau, ${ }^{a}$ Michaël De Paolis, ${ }^{a}$ Julien Legros $^{a}$ and Isabelle Chataigner ${ }^{\mathrm{a}, \mathrm{b}^{*}}$

The indol(in)e building block is one of the "privileged-structures" for the pharmaceutical industry since this fragment plays a central role in drug discovery. While the electron-rich character of the indole motif has been investigated for decades, exploiting the electrophilic reactivity of 3-nitroindole derivatives has recently been put at the heart of a wide range of new, albeit challenging, chemical reactions. In particular, dearomatization processes have considerably enriched the scope of $\mathrm{C} 2=\mathrm{C} 3$ functionalizations of these scaffolds. This feature article showcases this remarkable electrophilic reactivity of 3-nitroindoles with electron-rich species and highlights their value to generate diversely substituted indol(in)es. This compilation underlines how these heteroaromatic templates have gradually become model substrates for electron-poor aromatic compounds in dearomatization strategies.

\section{Introduction}

Indoles and their derivatives are important scaffolds in organic chemistry. ${ }^{1}$ Notably, the indoline motif has found major applications as biologically relevant compound for instance, in the indole alkaloids family with aspidospermine or vindoline molecules as salient examples (Scheme 1). These patterns are also found in useful ligands and organocatalysts. For many years, indole dearomatization strategies have led to elegant alkaloids syntheses mainly by taking advantage of the well-recognized C3-nucleophilicity of this electron-rich heterocycle. $^{2}$ Complementarily, indoles substituted by electron-withdrawing groups, in particular 3-nitroindole derivatives 1 , have been reported to exhibit an unexpectedly remarkable reactivity toward different electron-rich species, particularly in cycloaddition or annulation reactions. ${ }^{3}$ This has led to the expedient synthesis of functionalized indolines, which often retain a tetrasubstituted centre at the cis 5membered cycle junction. The $\mathrm{C} 2=\mathrm{C} 3$ double bond of nitroindoles can indeed behave either as a dienophile, a dipolarophile or a Michael acceptor (Scheme 1). Complementarily, the $\mathrm{C} 2=\mathrm{C} 3-\mathrm{N}=\mathrm{O}$ system of 3-nitroindoles has been shown to exhibit a heterodienic character. Herein we present an overview of these reactivities of 3-nitroindoles towards different electron-rich species, mainly in (formal) cycloaddition reactions, including catalytic and stoichiometric methodologies. Reductive transformations of 3-nitroindoles for the generation of 3-aminoindole derivatives, are not discussed here.

\footnotetext{
a. Normandie Université, INSA Rouen, UNIROUEN, CNRS, COBRA Laboratory, F76000 Rouen, France. E-mail: isabelle.chataigner@univ-rouen.fr

b. Present address: Sorbonne Université, Laboratoire de Chimie Théorique, UMR 7616 CNRS, 75005 Paris, France.

+ Footnotes relating to the title and/or authors should appear here.

Electronic Supplementary Information (ESI) available: [details of any supplementary information available should be included here]. See DOI: $10.1039 / x 0 x \times 00000 x$
}

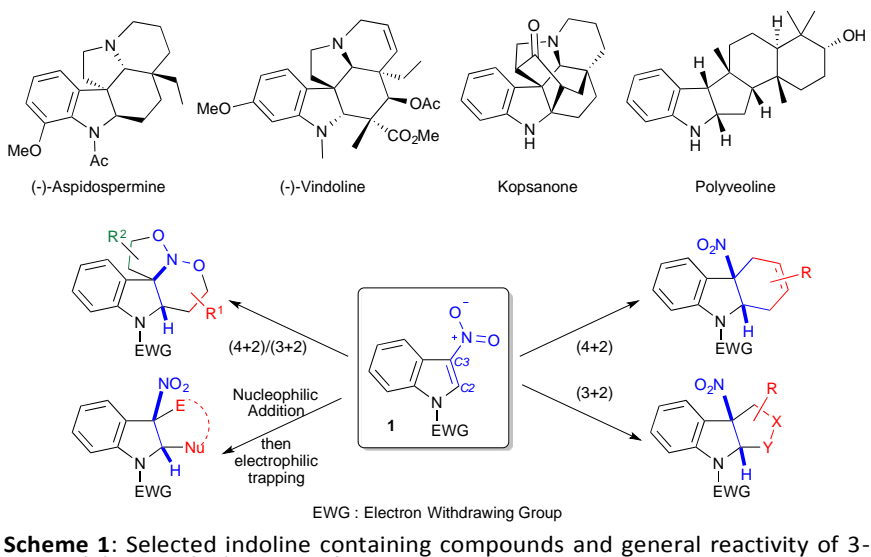

Scheme 1: Selected indoline containing compounds and general reactivity of 3 nitroindoles 1 with electron-rich species

\section{2. (3+2) (Formal) cycloadditions}

\section{With azomethine ylides and related dipoles}

$(3+2)$ Cycloaddition reactions involving electron-poor indoles were first reported by Gribble et al., in 1998, in the presence of mesoionic münchnones (1,3-oxazolium-5-olates) $\mathbf{2 a - b}$, bearing the same substituents in position 2 and 4 . The reactive species were generated in situ, using the appropriate $\mathrm{N}$-acylamino acid derivative in the presence of $\mathrm{N}, \mathrm{N}^{\prime}$ diisopropylcarbodiimide (DIPC) as dehydrating agent. These electron-rich 1,3-dipoles were thus reacted with 3-nitroindoles 1, protected/activated as $\mathrm{N}$-carbamates or -sulfonamides, in refluxing THF. At this temperature, the $(3+2)$ cycloadditions

could be achieved and the bridged tetracyclic cycloadduct intermediate $\mathbf{3}$ instantaneously lost carbon dioxide and nitrous acid to form the re-aromatized pyrrolo[3,4- $b]$ indoles 4, isolated in moderate to good yields (Table 1 , entries $1-4){ }^{4}$ 
Table 1. Reactions of 3-nitroindoles with mesoionic münchnones

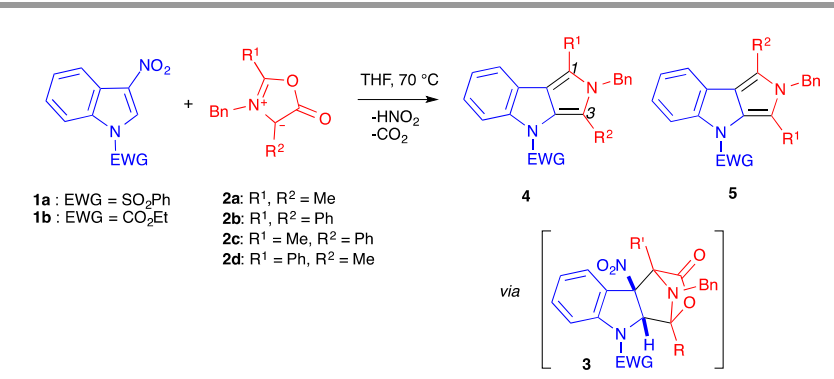

\begin{tabular}{cccccc}
\hline Entry & $\mathrm{EWG}$ & $\mathrm{R}^{1}$ & $\mathrm{R}^{2}$ & 4/5 ratio & Yield (\%) $^{\text {a }}$ \\
\hline 1 & $\mathrm{SO}_{2} \mathrm{Ph}$ & $\mathrm{Me}$ & $\mathrm{Me}$ & - & 67 \\
2 & $\mathrm{SO}_{2} \mathrm{Ph}$ & $\mathrm{Ph}$ & $\mathrm{Ph}$ & - & 65 \\
3 & $\mathrm{CO}_{2} \mathrm{Et}$ & $\mathrm{Me}$ & $\mathrm{Me}$ & - & 39 \\
4 & $\mathrm{CO}_{2} \mathrm{Et}$ & $\mathrm{Ph}$ & $\mathrm{Ph}$ & - & 60 \\
5 & $\mathrm{SO}_{2} \mathrm{Ph}$ & $\mathrm{Me}$ & $\mathrm{Ph}$ & $\geq 6: 94$ & 74 \\
6 & $\mathrm{SO}_{2} \mathrm{Ph}$ & $\mathrm{Ph}$ & $\mathrm{Me}$ & $70: 30$ to $90: 10$ & 76 \\
7 & $\mathrm{CO}_{2} \mathrm{Et}$ & $\mathrm{Me}$ & $\mathrm{Ph}$ & $5: 95$ to $0: 100$ & 65 \\
8 & $\mathrm{CO}_{2} \mathrm{Et}$ & $\mathrm{Ph}$ & $\mathrm{Me}$ & $50: 50$ to $60: 40$ & 89
\end{tabular}

a: overall yield

Two years later, the same group used unsymmetrical münchnones $\mathbf{2 c - d}$ in the same transformation (Table 1, entries $5-8) .^{5}$ Surprisingly, the regioselectivity displayed in the formation of the dihydropyrrolo[3,4-b]indoles 4 and/or 5 did not systematically follow the Frontier Molecular Orbital (FMO) theory rules. The major or exclusive product was the one where the phenyl group is in position 1 of the isolated dihydropyrrolo[3,4-b]indole. Although the exact reasons for this regioselectivity were not quite clear, the authors proposed that either favourable $\pi$-interactions between the indole nitro group and the phenyl ring of the münchnone in the transition state could induce the observed regioselectivity, or that it may be a consequence of a highly asynchronous transition state where bond making between the methylated carbon atom of the münchnone and the $\mathrm{C} 2$ of the nitroindole precedes bond making involving the phenyl substituted carbon atom of the münchnone, for steric reasons. Noteworthy, the indolic nitrogen atom has to bear an electron-withdrawing group for the reaction to proceed, as $N$-methyl-3-nitroindole was completely recovered after $24 \mathrm{~h}$ of reflux in the presence of 2d. This requirement will be found in many other transformations involving 3-nitroindoles as electrophilic species.

In 2007, Gribble and coll. described non-stabilized azomethine ylides as suitable 1,3-dipoles for the $(3+2)$ cycloaddition of 3-nitroindoles. ${ }^{6}$ Azomethine ylides 6 were classically generated in situ from the corresponding $\alpha$-amino acids and paraformaldehyde in refluxing toluene. In this case, treatment of 3-nitroindoles $\mathbf{1} \mathbf{a}-\mathbf{b}$ with an excess of dipole precursor cleanly afforded the dearomatized hexahydropyrrolo[3,4-b]indoles 7a-c, in good to excellent yields, without the loss of nitrous acid (Table 2, entries 1-3). 2Nitroindoles proved also reactive toward the same dipole in these conditions. In contrast however, attempting the cycloaddition with 1,2-bis(phenylsulfonyl)indole failed, underlying the importance of the nitro group for this transformation. In 2011, our group revisited these $(3+2)$ dearomative cycloadditions with the same non-stabilized azomethine ylide $\mathbf{6 a}$, generated this time from hemiaminal $\mathbf{8 a}$ at $0{ }^{\circ} \mathrm{C}$ under TFA catalysis. ${ }^{7}$ These conditions were compatible with different nitroarenes, including nitrobenzenes and were applied to 3-nitroindoles to deliver the corresponding dearomatized cycloadduct in high yields (Table 2, entries 4-7). ${ }^{8}$ The lability of some protecting groups such as tertbutoxycarbonyl (Boc) or trifluorosulfonyl (Tf) limited their use in this case but these milder thermal conditions allowed to significantly decrease the dipole precursor quantity from 5 to 1.2 equiv. Noteworthy, this $(3+2)$ cycloaddition with azomethine ylides generated in acidic conditions not only applies to 3-nitroindoles but could be extended to indoles bearing keto, ester, or cyano groups in position $3 .^{8,9}$ More recently, Lequeux and coll. developed a photocatalyzed reaction for the formation of azomethine ylide $\mathbf{6 a}$, at room temperature, under non-acidic conditions. ${ }^{10}$ To this end, they used Eosin $Y(E Y)$, an organic dye, to decompose hemiaminal 8a and generate the dipole under green light irradiation. Although the article focuses mainly on the preparation of fluorinated pyrrolidines, the authors included one example of a $(3+2)$ dearomative cycloaddition with $\mathrm{N}$-tosyl-3-nitroindole 1c, which showed excellent conversion of the heteroaromatic substrate under these photocatalyzed conditions (Table 2, entry 8).

Table 2: Reactions of 3-nitroindoles with non stabilized azomethine ylides 6

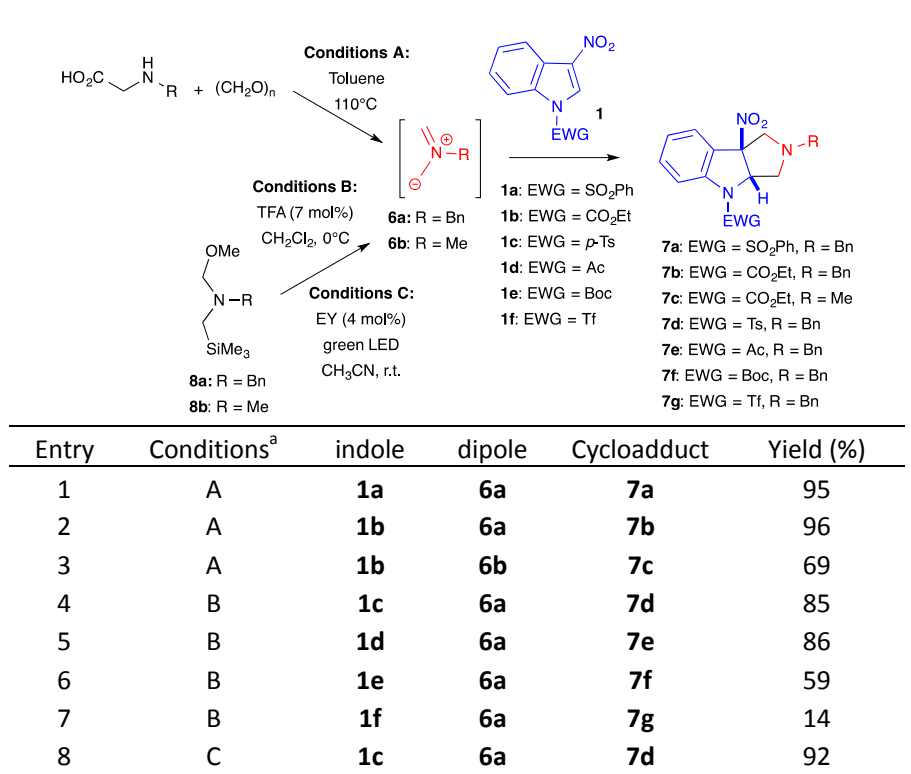

a: Conditions A: 5 equiv aminoacid, 12 equiv paraformaldehyde in toluene at $110^{\circ} \mathrm{C}$. Conditions B: 1.2 to 2 equiv $8 \mathrm{a}$, TFA ( $7 \mathrm{~mol} \%$ ) in $\mathrm{CH}_{2} \mathrm{Cl}_{2}, 0{ }^{\circ} \mathrm{C}$ to r.t.. Conditions $\mathrm{C}$ : 2 equiv $8 \mathrm{a}$, eosin $\mathrm{Y}$ disodium salt (4 mol \%) with a $5 \mathrm{~W}$ green LED in $\mathrm{CH}_{3} \mathrm{CN}$ at r.t..

In 2014, Arai and coll. reported the first example of an enantioselective $(3+2)$ dearomative formal cycloaddition involving 3-nitroindoles 1 (Scheme 2). ${ }^{11}$ The authors used 
glycine-derived imino esters 9 in the presence $\mathrm{Cs}_{2} \mathrm{CO}_{3}$ as base and $\mathrm{Cu}(\mathrm{OTf})_{2}$ associated to the chiral PyBidine ligand $\mathbf{1 0}$ as catalyst to form the reactive chiral enolate $\mathbf{1 1}$ acting as a surrogate of a stabilized azomethine ylide dipole. The proposed mechanism involves a stepwise transformation, via two anti-selective Michael/Mannich reactions. The PyBidine$\mathrm{Cu}(\mathrm{OTf})_{2}$ chiral complex would first drive the anti-attack on the 3-nitroindole. After $\mathrm{C}-\mathrm{N}$ single bond rotation, the least sterically hindered nitronate intermediate would cyclize, leading to the formation of pyrroloindolines $\mathbf{1 2}$ in good to excellent yields, with nearly perfect exo'-selectivity.

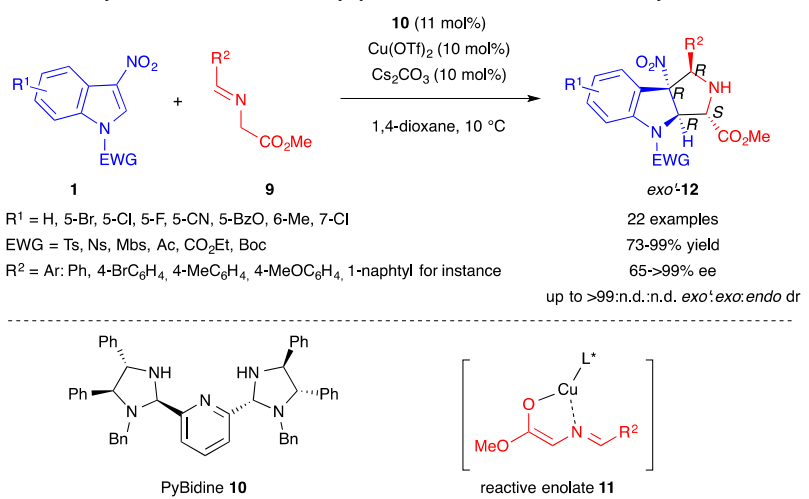

Scheme 2: Enantioselective $(3+2)$ formal cycloaddition of 3-nitroindoles with glycine-derived iminoesters

Two years later, Gerten and Stanley extended this kind of reactivity to enolates derived from alanine imino esters 13, generating a cycloadduct bearing a quaternary center at position 3 of the pyrrolidinoindoline 14 (Scheme 3). ${ }^{12}$ The authors used a catalytic system based on $\mathrm{Cu}(\mathrm{OTf})_{2}$ and bisphosphine ligand $(R)$-difluorphos to obtain good diastereoand enantio-selectivity. They also demonstrated the existence of a competitive non-catalyzed endo-selective reaction, but showed that the copper complex also catalyzed the epimerization of the endo-14 cycloadduct to the exo'-14 one.

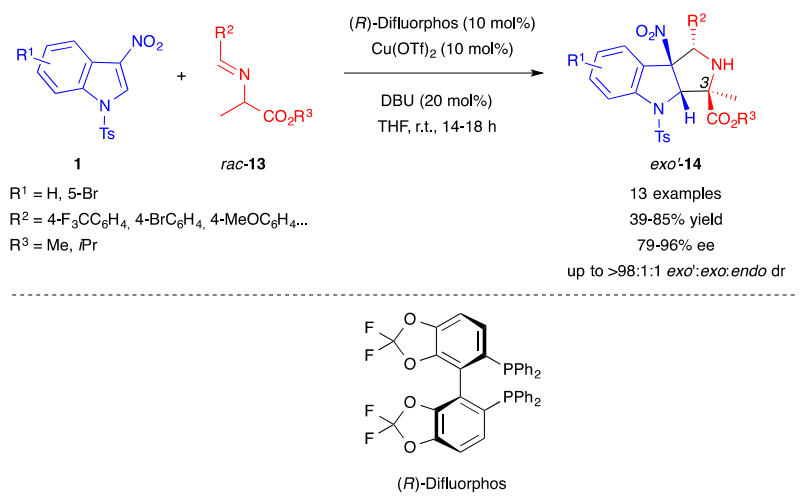

Scheme 3: Enantioselective $(3+2)$ formal cycloaddition of 3-nitroindoles with alanine-derived iminoesters 13.

In 2017, Wang and coll. reported the reactivity of 3nitroindoles 1 as dipolarophiles toward a different kind of nucleophilic 1,3-dipole, cyclic azomethine imines 15, in a catalyst-free transformation. ${ }^{13}$ The reaction proceeded smoothly in most organic solvents, ethyl acetate giving the best results to afford pyrazolidinic cycloadducts 16 in a diastereoselective fashion, with a diastereomeric ratio above
20:1 in all the reported examples (Scheme 4). According to the authors, this selectivity would come from the favourable $\pi-\pi$ interaction between the 6-membered aromatic rings of the indole and the azomethine imine.

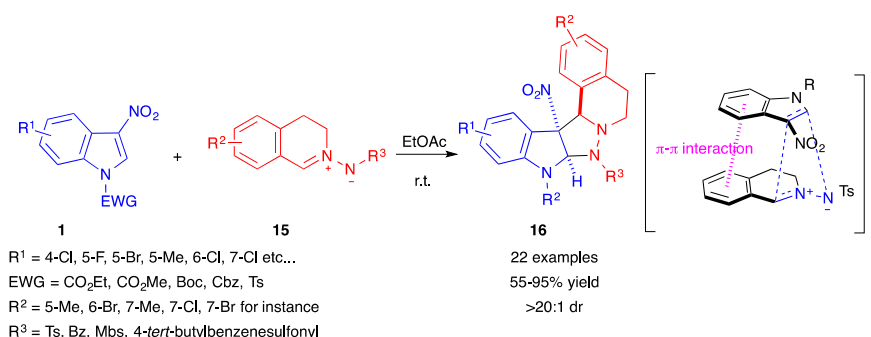

$\mathrm{R}^{3}=\mathrm{Ts}, \mathrm{Bz}, \mathrm{Mbs}$, 4-tert-butylbenzenesulfony

cheme 4: $(3+2)$ Dearomative cycloaddition of 3-nitroindoles 1 with cyclic azomethine imines 15

\section{Dipoles generated under palladium or copper catalysis}

Different types of nucleophilic 1,3-dipoles or surrogates can be formed under transition metal catalysis, such as palladium. In 2014, Trost et al. first used the palladium-catalyzed trimethylenemethane (TMM) cycloaddition methodology ${ }^{14}$ to explore the dearomatization of nitroarenes. By using TMM precursor $17, \mathrm{Pd}(\mathrm{dba})_{2}$ and the bisdiamidophosphite ligand $\mathbf{1 8}$, the authors were able to quantitatively dearomatize diverse nitroarenes, including nitroindoles. ${ }^{15}$ This process was the first in which an all-carbon 1,3-dipole generates methylidenecyclopentane containing structures in such dearomatizing $(3+2)$ formal cycloadditions. Applied to phenylsulfonyl- and Boc-protected 3-nitroindoles, in the racemic version of the reaction, performed in the presence of the racemic ligand 18, the corresponding cycloadducts 19 were obtained in quantitative yields (Scheme 5). With the chiral ligand, a $66 \%$ ee was obtained. A stepwise pathway is suggested for this transformation. The TMM dipole 20, generated in situ, would add to the $\mathrm{C} 2$ electrophilic position of the nitroindole. Then, in the second step of this formal cycloaddition process, the zwitterionic nitronate intermediate would cyclize via an intramolecular attack of the soft carbon nucleophile onto the $\pi$-allylpalladium.

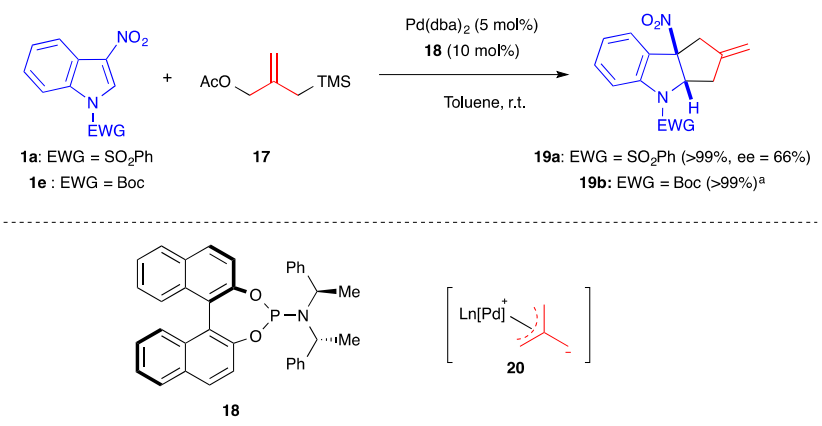

Scheme 5: Pd-catalyzed $(3+2)$ annulation with TMM.

${ }^{a}$ performed in the presence of the racemic ligand.

Three-membered rings bearing a vinylic appendage constitute relevant 1,3-dipole precursors in the presence of a transition metal such as palladium. ${ }^{16}$ In late 2016, the Hyland group reported the $\mathrm{Pd}$-catalyzed diastereoselective synthesis 
of pyrrolo[2,3-b]indoline using vinylaziridines $\mathbf{2 1}$ as dipole precursor. ${ }^{17}$ In the presence of phenanthroline (BPhen) ligand and $\mathrm{Pd}(\mathrm{dba})_{3} \cdot \mathrm{CHCl}_{3}$ as metal source, the authors were able to access pyrroloindolines $\mathbf{2 3}$ in high yields with good diastereoselectivity (Scheme 6). They proposed that the stereocontrol of this two-steps formal cycloaddition reaction relied on the substituent of the indole C4-position. With a proton at this position, the nitro-enolate intermediate would preferentially adopt the TS1 conformation, which may be stabilized by cation- $\pi$ interactions between the cationic $\pi$-allyl Pd complex and the electron-rich indole. This transition state would then lead to the trans-product. Alternatively, if the indole C4-position is substituted, the resulting steric repulsions could disrupt these interactions, leading to the less hindered TS2. Additionally, an ester at C4 would be able to interact with the $\pi$-allyl Pd complex, stabilizing TS2 even more, ultimately leading to the formation of cis-23.

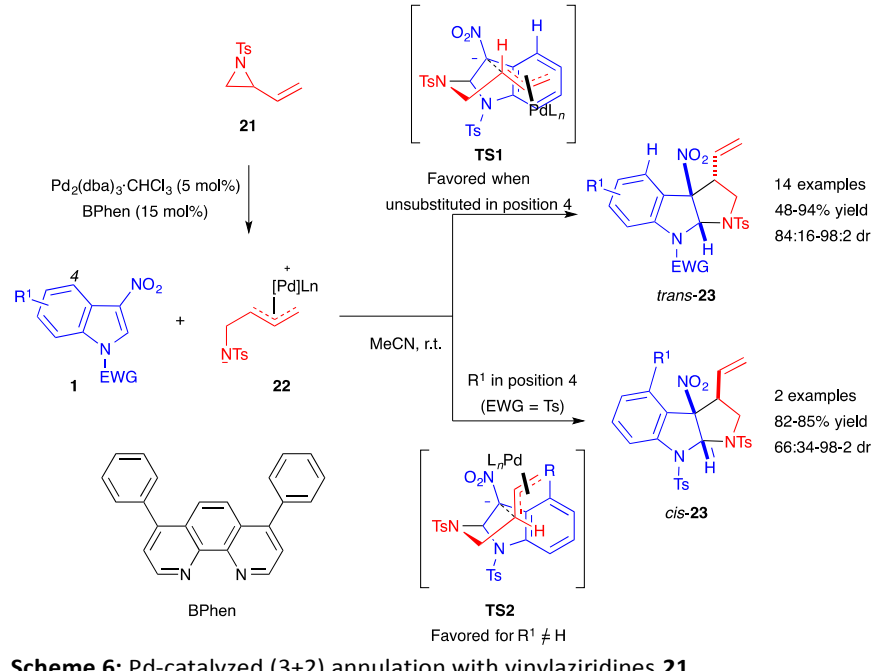

In 2018, Hou and coll. reported the enantioselective dearomative $(3+2)$ version of this reaction. ${ }^{18}$ The authors used cryogenic temperatures and chiral ferrocenyl phosphine ligand 24, to obtain high enantio- and diastereocontrol over the reaction between substituted 3 -nitroindoles 1 and $\mathrm{N}$-tosyl vinyl aziridines $\mathbf{2 1}$ (Scheme 7). In this case, cis-pyrroloindolines 23 were obtained in excellent yields, diastereomeric ratios and enantiomeric excesses. The reaction could be scaled up to a gram scale and the reaction products could be easily converted to amino pyrroloindolines for instance, by reduction of the nitro group using the $\mathrm{TMSCl} / \mathrm{Zn}$ system.

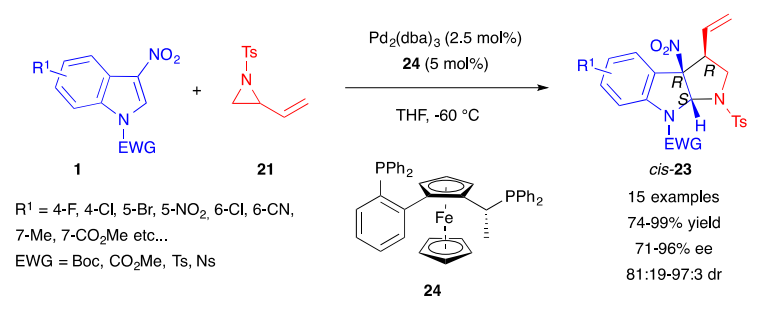

Scheme 7: Enantioselective $(3+2)$ annulation of 3-nitroindoles with vinyl aziridines.
Almost simultaneously to Hyland work, Vitale and coll. reported a Pd-catalyzed $(3+2)$ cyclopentannulation of 3nitroindoles with various vinylcyclopropanes (VCPs) 25, bearing cyano or ester electron-withdrawing groups. ${ }^{19}$ Their method, involving all-carbon dipoles, allowed the diastereoselective dearomatization of a wide range of nitroindoles, furnishing the corresponding cyclopenta[b]indolines $\mathbf{2 7}$ in good to excellent yields and moderate to excellent diastereoselectivities (Scheme 8). The method selectively produced the cis-isomer of $\mathbf{2 7}$. In order to account for this divergent diastereoselectivity compared to Hyland work, the authors proposed that, after Michael addition of the Pd-VCP 1,3-dipole 26 to the electrophilic 3nitroindole 1 , subsequent cyclization would occur through either transition state TS1 or TS2, where the forming cycle is not anymore on the indole side. The latter would be favoured as the $\pi$-allyl moiety would adopt a pseudo-equatorial conformation, minimizing 1,3-diaxial interactions.

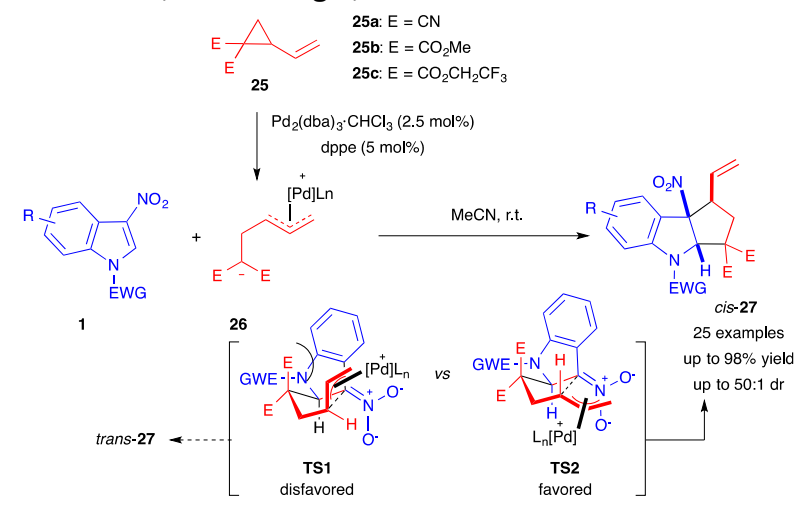

Scheme 8: Pd-catalyzed dearomative $(3+2)$ annulation with VCPs 25 and proposed transition states.

Soon after, Hyland also disclosed the use of 2vinylcyclopropane-1,1-dicarboxylates as all-carbon dipole precursor for the synthesis of cyclopenta[b]indolines $27 .{ }^{20}$ The authors used the previous catalytic system, composed of $\mathrm{Pd}$ and BPhen, to achieve efficient dearomative $(3+2)$ annulation of 3-nitroindoles 1 (Scheme 9). They were able to control the diastereoselectivity of the annulation process by adding $n \mathrm{Bu}_{4} \mathrm{NI}$ as a source of halide. The authors proposed that this could enhance the $\pi-\sigma-\pi$ interconversion rate between the different transition states, leading, in most cases, to the probably more thermodynamically stable trans-isomers. As in their previous report, an ester substituent at the indole C4position caused an inversion of the diastereoselectivity, and cis-27 ended up being the major product. Only in this case, the halide additive was not required, as it was detrimental to both the yield and the $d r$. 


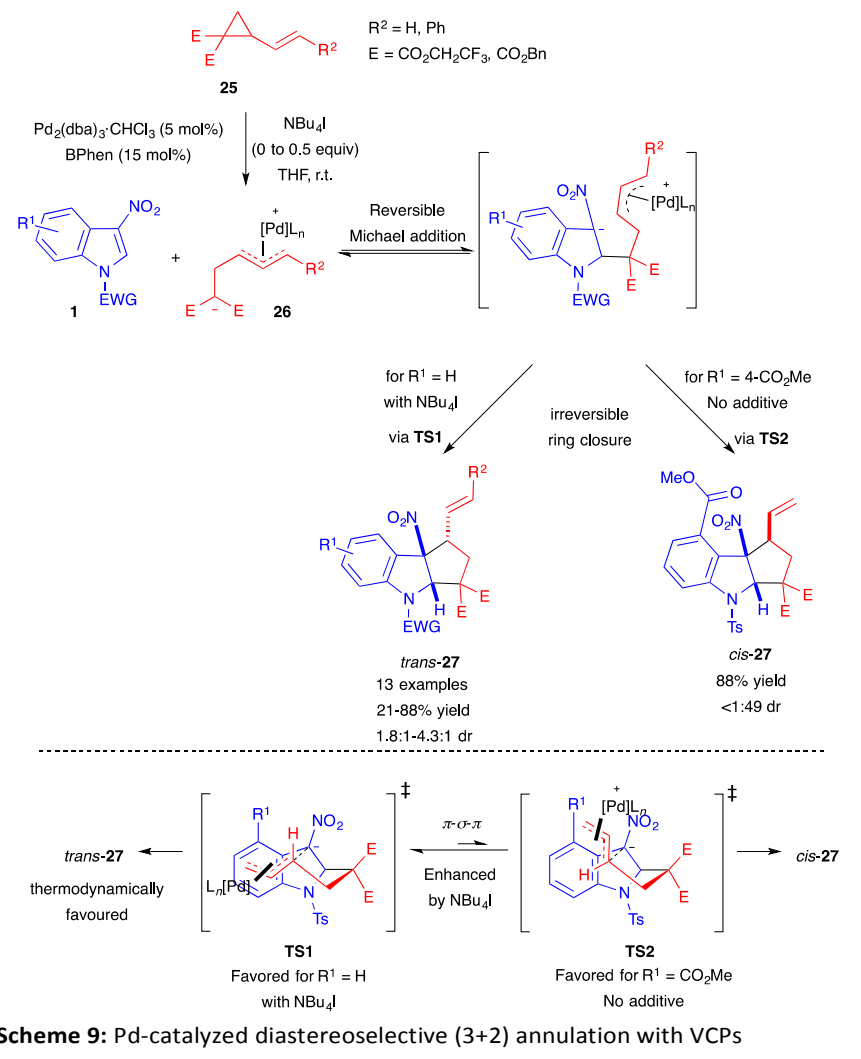

In 2018, Shi and coll. used dicyano VCPs 25a to develop an enantioselective version of this dearomative $(3+2)$ cyclopentannulation of 3-nitroindoles. ${ }^{21}$ The authors found that their optimal catalytic system, composed of $\mathrm{Pd}(\mathrm{dba})_{2}$ and chiral phosphoramidite ligand $\mathbf{2 8}$, was able to convert a range of 3-nitroindoles to the corresponding polycyclic adduct $\mathbf{2 7}$ in good yields with high enantioselectivity but still with a moderate cis diastereoselectivity (Scheme 10).

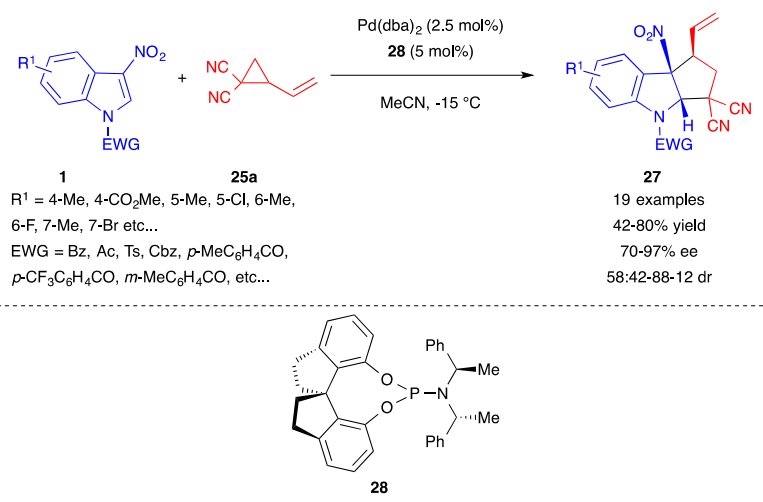

Scha.

Simultaneously, Wang and coll. developed strategies for the asymmetric $(3+2)$ annulation of 3-nitroindoles with both vinyl aziridines $\mathbf{2 1}$ and VCPs $25 .{ }^{22}$ The authors used chiral bis(oxazoline) (Box) ligands 29a-b to convert 3-nitroindoles 1 into the corresponding highly diastereo- and enantioenriched pyrrolo[2,3- $b]$ indolines trans-23 and cyclopenta[ $[b]$ indolines trans-27, albeit with lower diastereoselectivity (Scheme 11).

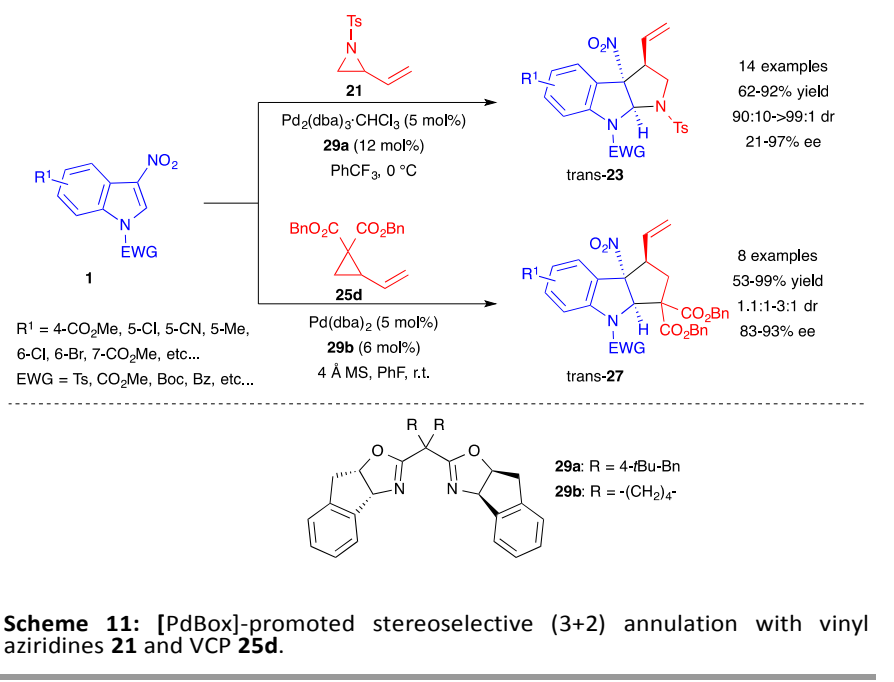

Guo, You and coll. then reported a stereodivergent method for the synthesis of tetrahydrofuroindoles by Pdcatalyzed asymmetric $(3+2)$ annulation of 3-nitroindoles with vinyl oxiranes $30 .^{23}$ By using chiral phosphinooxazoline ligand 31, a large scope of substituted 3-nitroindoles 1 could be reacted with epoxybutenes $\mathbf{3 0}$ in good to excellent yields and stereoselectivities (Scheme 12). Unlike in many dearomatizing annulations of this type, electron-enriched indoles bearing a 5or 6-methoxy moiety were found to be suitable substrates. Additionally, by choosing either toluene, or a much more polar solvent such as acetonitrile, the authors were able to direct the product diastereoselectivity toward its cis- or trans-isomer. To explain this stereodivergency, they performed a number of mechanistic experiments, ultimately proposing a mechanism (Scheme 11). Oxidative addition of the $\mathrm{Pd}^{(0)}$ catalyst to the oxirane would lead to the ring-opened 1,3-dipole 32. In a nonpolar solvent such as toluene (path a), this intermediate would form a tight ion pair, decreasing its nucleophilicity and making the first dearomative Michael addition step ratedetermining. Fast cyclization of resulting intermediate $\mathbf{3 3}$ would then occur, giving preferentially cis-34. In contrast, a more polar solvent like acetonitrile (path b) would drive the rapid formation of intermediate, while stabilization of the zwitterion $\mathbf{3 3}$ would slow the cyclization step, thus making it rate limiting. This would give enough time for $\pi-\sigma-\pi$ inversion of the Pd-allyl complex, leading to the formation of diastereoisomer trans-34. 


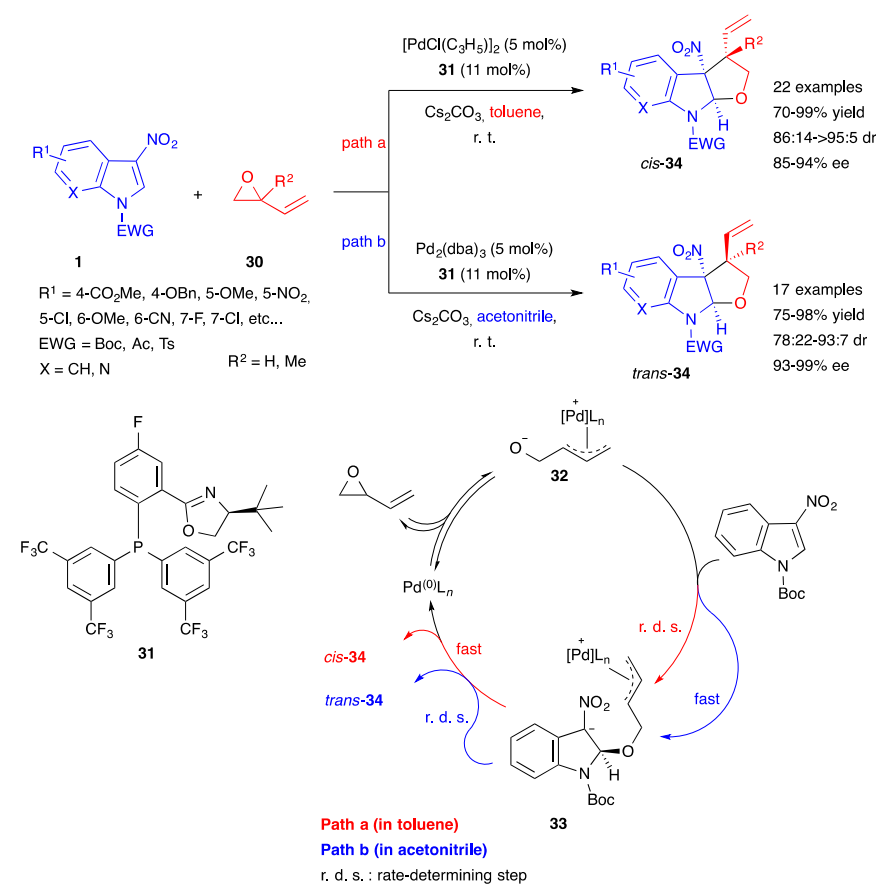

Sch

More recently, Vitale and coll. reported a different type of dearomative $(3+2)$ annulation of 3-nitroindoles, involving this time propargylic nucleophiles and copper catalysis. ${ }^{24}$ Using copper(II) triflate, triphenylphosphine and cesium carbonate, the authors were able to convert a wide range of 3-nitroindoles $\mathbf{1}$ to the corresponding cyclopenta[ $b]$ indolines, pyrrolo[2,3-b]indolines and furo[2,3$b$ ]indolines $\mathbf{3 5}$ with propargylic partners $\mathbf{3 3}$ (Scheme 13). They also demonstrated the possibility for an asymmetric version of their reaction, using $(R)$-difluorophos (Scheme 3 ) as chiral ligand, albeit with modest ee (51\%). The authors proposed the mechanism shown on Scheme 13. Reduction of $\mathrm{Cu}(\mathrm{OTf})_{2}$ to the copper(I) catalyst, followed by complexation to the propargylic nucleophile $\mathbf{3 5}$ may form the $\pi$-alkyne complex $\mathbf{A}$, possibly in equilibrium with the alkynylcopper(I) derivative $\mathbf{A}^{\prime}$. A would undergo deprotonation to give 1,3-dipole $\mathbf{B}$, which would then react with nitroindole $\mathbf{1}$ to form a nitronate intermediate adduct. It would then cyclize in a pseudo-chair-like transition state, either through an anti-carbocupration (C) or a syncarbocupration $\left(\mathbf{C}^{\prime}\right)$ pathway, forming intermediate $\mathbf{D}$. Subsequent protodecupration with either hydrogenocarbonate, $\mathbf{3 5}$ or A would then afford cycloadduct 36 , as well as regenerating copper(I).
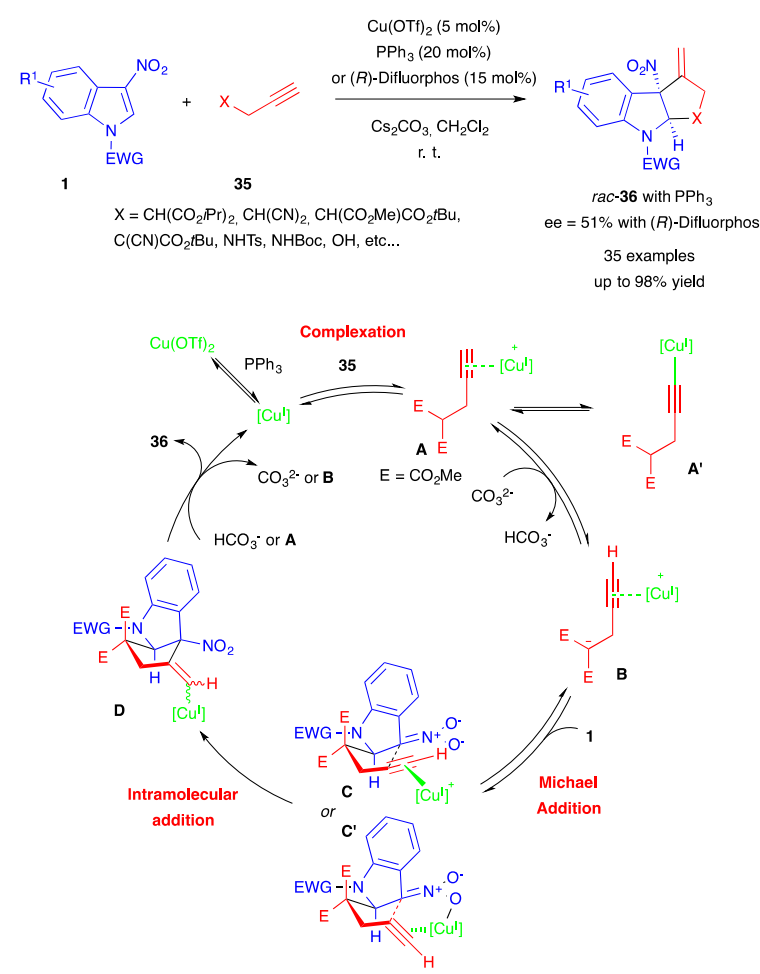

Scheme 13: Cu-catalyzed racemic dearomative annulation with propargylic nucleophiles.

23. 1,3-Dipoles (or surrogates) generated in the presence of organic promoters

3-Nitroindoles are prone to react with enolates in nucleophilic addition reactions (vide infra). If the enolate anion bears an additional reactive site, in position 3 respective to the enolate carbon atom this can lead to an intramolecular cyclization and an overall formal $(3+2)$ cycloaddition process. Different enolates of this kind have been used throughout the years in such annulation reactions.

In 1997, Gribble and coll. first showed that 3nitroindoles 1 protected/activated as $N$-benzyl, $N$-pyridyl or $\mathrm{N}$-ethoxycarbonyl compounds could react with ethyl isocyanoacetate $\mathbf{3 7 a}$ or tosylmethyl isocyanide $\mathbf{3 7 b}$ in the presence of an organic base such as DBU (Scheme 14). ${ }^{25}$ Compounds $\mathbf{3 5}$ were formed, according to a Barton-Zard reaction, by conjugate nucleophilic addition of the enolate anion on the nitroindole substrate, followed by intramolecular 5-endo-dig cyclisation of the intermediate nitronate on the isocyanide. After, reprotonation of the formal cycloadduct, base-catalysed elimination of the nitro group and tautomerization leading to the formation of a pyrrole ring, the compounds $\mathbf{3 8}$ were obtained in moderate to high yields, depending mainly on the electron-withdrawing character of the nitrogen substituent of $\mathbf{1}\left(\mathrm{CO}_{2} \mathrm{Et}>\right.$ pyridyl>benzyl). The more attracting groups probably facilitated the key initial nucleophilic addition. When even more electron-withdrawing groups such as phenylsulfonyl were used, however, an abnormal regioselectivity was observed for this reaction, 
leading to a ring opening/rearrangement and a regioisomeric cycloadduct (vide infra, §51). ${ }^{26}$

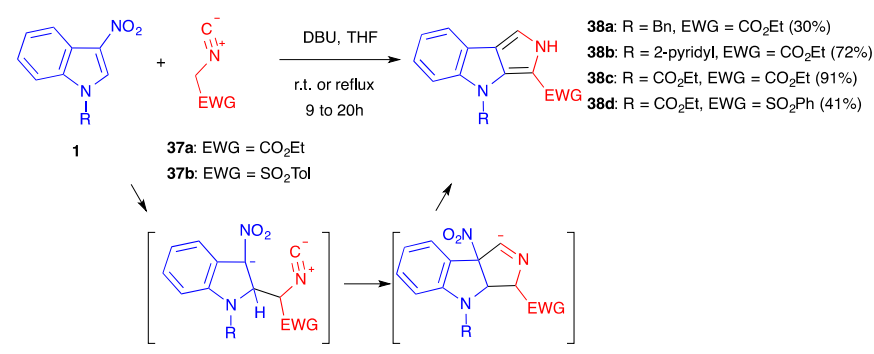

Scheme 14: Barton-Zard reactions involving 3-nitroindoles

In 2015, Yuan and coll. reported the organocatalyzed asymmetric Michael/cyclization cascade reaction between 3nitroindoles 1 and 3-isothiocyanato oxindoles $39 .{ }^{27}$ Using the chiral bifunctional catalyst $\mathbf{4 0}$, based on the quinine structure, the authors were able to access a wide range of spirocyclic oxindoles $\mathbf{4 1}$ in excellent yields with great stereoselectivity (Scheme 15). The first step of the process was the Michael addition of the enolate derived from 39 to the electrophilic C2 position of the activated 3-nitroindole and was followed by an intramolecular cyclization on the electrophilic central carbon atom of the isothiocyanide. The same year, this group updated the transformation by switching the organocatalyst to a $\mathrm{Zn}(\mathrm{OTf})_{2}$ /diphenylamine-linked bis(oxazoline) complex (Scheme 15). ${ }^{28}$ The use of the Lewis acid catalyst with ligand $\mathbf{4 2}$ improved the results. The proposed mechanism of this latter process suggested a transition state where the catalytic complex plays a dual role. Indeed, the $\mathrm{Zn}$ (II) core would activate the 3-nitroindole while the $\mathrm{NH}$ link would serve as Lewis base, directing the 3-isothiocyanato oxindole for the key Michael addition step.
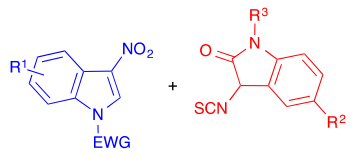

1

$\mathrm{R}^{1}=4-\mathrm{Cl}, 5-\mathrm{Cl}, 5-\mathrm{OMe}, 5-\mathrm{OBn}, 6-\mathrm{Cl}, 7-\mathrm{Me}$ etc.

$\mathrm{EWG}=\mathrm{Ts}, \mathrm{Bs}, \mathrm{Ms}, \mathrm{Ns}, \mathrm{Ac}, \mathrm{Cbz}, \mathrm{CO}_{2} \mathrm{Et}, \mathrm{Boc}$

$R^{2}=H, F, M e$

$\mathrm{R}^{3}=\mathrm{Me}, \mathrm{Et}, \mathrm{Bn}, \mathrm{Ph}$

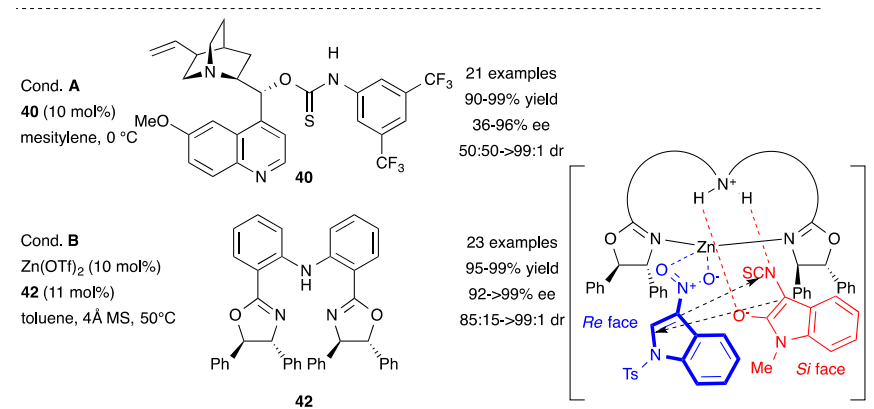

Scheme 15: Organocatalyzed $\underline{v s}$ metal-catalyzed asymmetric spirocyclic oxindoles synthesis.

In 2019, Yuan and coll. reported a different type of asymmetric dearomative $(3+2)$ annulation of 3 -nitroindoles, triggered by a thiol $\mathbf{4 3}$ bearing a Michael acceptor moiety. ${ }^{29}$ They used a chiral tertiary amine-squaramide bifunctional organocatalyst $\mathbf{4 4}$ to control the enantioselective, stepwise double Michael addition between ethyl 4-mercapto-2butenoate $\mathbf{4 3}$ and 3-nitroindoles 1 (Scheme 16). This reaction tolerated a wide range of substitution on the electrophilic 3-nitroindoles and furnished tetrahydrothiopheindolines 45 in good to excellent yields with great enantio- and diastereoselectivity.

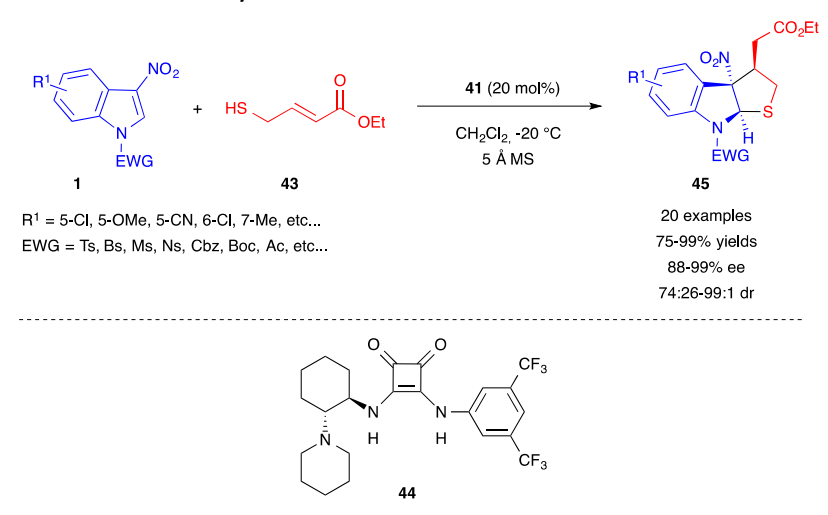

Scheme 16: Organocatalyzed thiol-triggered $(3+2)$ annulation of 3-nitroindoles.

In 2019, almost simultaneously, different publications reported the reactivity of allenoates $\mathbf{4 6}$ toward 3-nitro-indole derivatives 1 in the presence of phosphine organocatalysts, in the so-called Lu annulation, to generate fused cyclopentannulated indolines. ${ }^{30,31,32,33,34,35}$ In the literature, Lu annulation processes have been shown to lead to two possible alpha and gamma regioisomers, the result of the two possible additions of the mesomeric 1,3-dipole A or B. Thus, the nucleophilic addition of the dipole to the position 2 of the electrophilic nitroindole can potentially lead to the formation of two regioisomers $\mathbf{4 7}$ and $\mathbf{4 8}$. In all these publications, the unique formation of the $\alpha$-cycloadduct $\mathbf{4 7}$ was observed (Scheme 17).

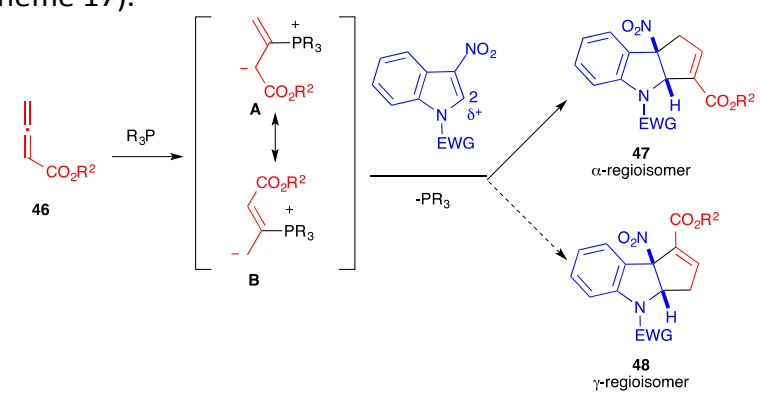

Scheme 17: Regioselectivity of the dearomative $(3+2)$ Lu annulation with 3nitroindoles.

The mechanism proposed for this reaction and supported by DFT calculations, ${ }^{30,31}$ involves, first, the addition of the phosphine catalyst to the allenoate leading to the reactive 1,3-dipole $\mathbf{A}$, stabilized by the positive $\mathrm{P}^{+}--_{-}^{-}$ interaction. $^{31}$ The electron-rich dipole would then add regioselectively to the nitroindole dipolarophile to furnish nitronate $\mathbf{C}$, that would cyclize intramolecularly generating the formal $\alpha$-cycloadduct $D$. A proton shift is then required to produce $\mathbf{E}$. The presence of water molecules (or other proton relay) in the reaction medium would facilitate this otherwise highly energetic reaction. The formal cycloadduct $\mathbf{4 7}$ would then be formed by expulsion of the catalyst (scheme 18). Lu 
and coll. showed, through intermolecular competition experiments, that the nucleophilic addition of the dipole $\mathbf{A}$ onto 1 was the rate determining step in his case, involving $\gamma$-unsubstituted allenoates. ${ }^{27}$

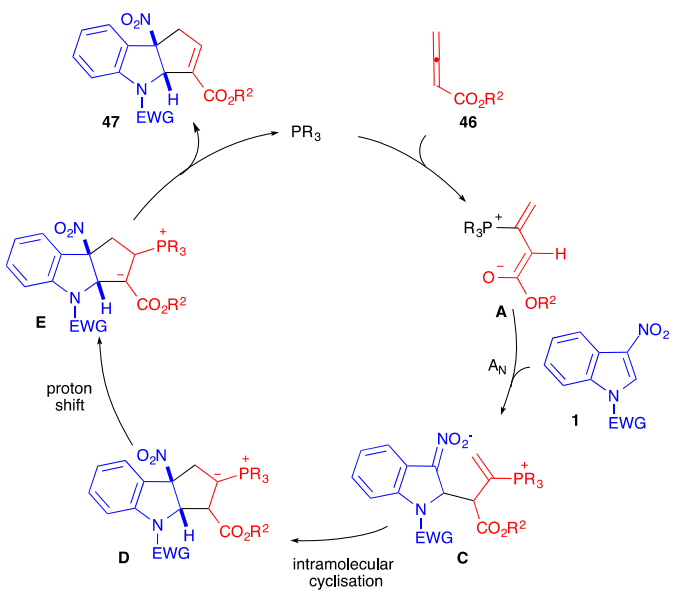

Scheme 18: Catalytic cycle proposed for this $(3+2)$ annulation reaction

These $(3+2)$ dearomative cycloadditions were first reported by the Zhang and Lu groups, with unsubstituted allenoates $\mathbf{4 6}$ in the presence of dipeptidic phosphine catalysts 46 and 47. Different indoles 1 were dearomatized in a highly enantioselective fashion with these chiral bifunctional organocatalysts (Scheme 19). ${ }^{30,31}$ These catalysts would play a dual role, here, allowing the formation of the reactive dipole while activating the electrophilic nitroindole by hydrogen bonds in the meantime, thus bringing the reactive parts in a close environment. The presence of the amido protons probably also helped the proton shift required within the catalytic cycle. ${ }^{34,35}$ SPINOL-derived phoshine and amidophosphine derived from cyclohexyl-1,2-diamine could also be used as chiral organocatalysts in these reactions albeit with lower enantioselectivity. ${ }^{32,33}$

Zhang and coll. showed that indoles 1 protected as carbamates were more reactive than their sulfonamidic analogues. $^{30}$ This was correlated by the authors to the unexpected lower aromaticity of the former, a feature already observed on different electrophilic indole derivatives in $(4+2)$ cycloadditions processes. ${ }^{36}$
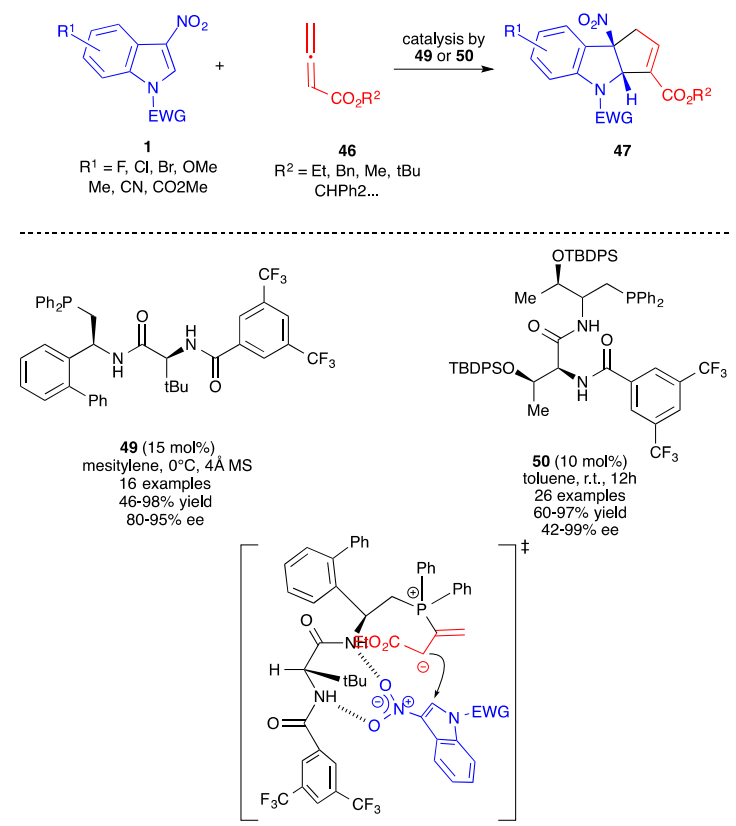

Scheme 19: Enantioselective $\mathrm{Lu}(3+2)$ annulations with 3-nitroindoles in the presence of bifunctional dipeptidic phosphine organocatalysts.

Bandini and coll. reported the formal $(3+2)$ cycloaddition in the presence of $\gamma$-alkyl allenoates $\mathbf{5 1}$ bearing methyl

or $n$-propyl substituents. ${ }^{34}$ In the presence of the commercially available tri(p-methoxyphenyl)phosphine, the corresponding $\alpha$-cycloadducts $\mathbf{5 2}$ were formed in good to high yields and diastereoselective ratios ranging from $2: 1$ to $3.5: 1$, with a preferentially trans relative stereochemistry (Scheme 20).

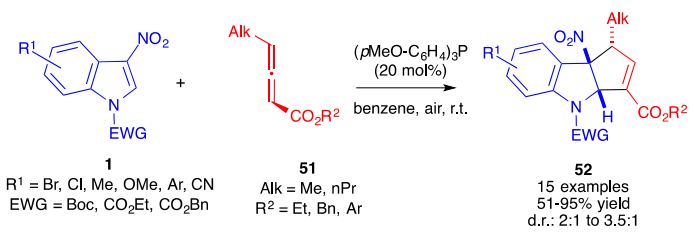

Scheme 20: Dearomative $(3+2)$ annulations with 3-nitroindoles 1 in the presence of $\gamma$-alkyl allenoates.

Soon after, we reported the dearomative $(3+2)$ annulation of 3-nitroindoles 1 with other $\gamma$-substituted allenyl ester 53 (Scheme 21). ${ }^{35} \gamma$-Allenoates bearing more hindered alkyl groups such as $i \mathrm{Pr}$ or $\mathrm{Cy}$, with diverse functionalities such as alkenes, alkynes, protected alcohols or amines, or substituents derived from biomolecules such as amino and deoxycholic acids proved to react smoothly with 3-nitro- $N$-Ts indoles $\mathbf{1 c}$ in the presence of a commercially available phosphine catalyst $\left(\mathrm{PPh}_{3}\right.$ or $\left.\mathrm{PBu}_{3}\right)$. The reaction also led to the exclusive formation of the functionalized $\alpha$-regioisomer 54 , in moderate to good yields and with diastereoselectivities up to $3: 1$, in favour of the trans diastereomer. The reaction was best performed in the presence of water to facilitate the $[1,2]-H$ shift. 

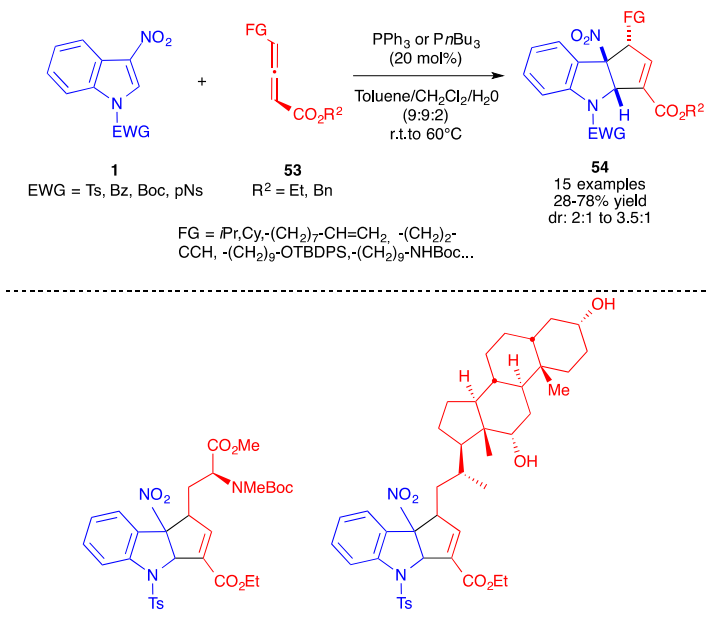

Scheme 21: $(3+2)$ Formal cycloadditions in the presence of $\gamma$-functionalized allenoates 53 .

Starting from a different substrate that is an isatinderived Morita-Baylis-Hillman (MBH) carbonate 55, Gao, Ge, Tian and coll. recently showed that a related enantioselective $(3+2)$ annulation reaction could be performed on electrophilic 3-nitroindoles $\mathbf{1}$, in the presence of a bifunctional DMAPthiourea organocatalyst $56 .{ }^{37}$ Spirooxindoles 57 , bearing a cyclopentannulated indoline and three consecutive stereocenters, were thus obtained in high yields and enantioselectivities (Scheme 22).

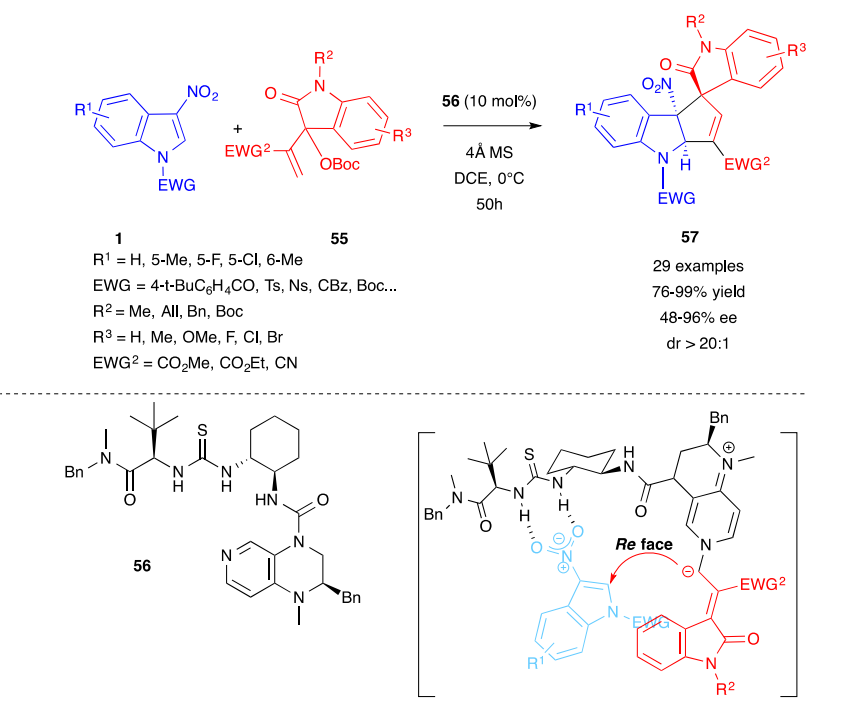

Scheme 22: $(3+2)$ annulation between 3-nitroindoles 1 and isatin-derived $\mathrm{MBH}$ carbonate $\mathbf{5 5}$ in the presence of the bifunctional organocatalyst $\mathbf{5 6}$.

\section{3. (4+2) (Formal) cycloadditions}

Complementary to $(3+2)$ cycloaddition/annulation reactions, the $(4+2)$ reactions involving 3-nitroindoles 1 allow to generate tricyclic indolines combining 6-5-6 rings, encountered in (polyhydro)carbazole derived structures. In this case the $\mathrm{C} 2=\mathrm{C} 3$ double bond is involved as an electronpoor dienophile with electron-rich 1,3-dienes or 1,4-dipoles.

\section{1. (4+2) Cycloadditions}

Before the $(3+2)$ reactions mentioned above were described, Wenkert et al. first reported in 1988 the normal electron demand (NED) Diels-Alder reaction involving different electron-poor indole derivatives. ${ }^{38}$ 3-Nitroindoles were the most reactive ones and 1-benzenesulfonyl-3-nitroindole $\mathbf{1 b}$ reacted with a 12 -fold excess of isoprene $(\mathbf{5 8})$ to generate a 16:3:5:1 mixture of dihydrocarbazoles (59a and 59b) and carbazoles (60a and $60 \mathrm{~b}$ ) in an overall $65 \%$ yield (Scheme 23 ). With this neutral apolar electron-rich diene, more drastic conditions were needed compared to the $(3+2)$ cycloadditions/annulations described previously and the reaction was performed at high temperature $\left(155^{\circ} \mathrm{C}\right)$, for $26 \mathrm{~h}$. This led to the rearomatization of the primary cycloadducts by extrusion of nitrous acid and aromatization, by oxidation, into the corresponding carbazoles. The authors showed that the cycloaddition required the presence of an electronwithdrawing group on the nitrogen atom of the indole dienophile, a feature shared with the $(3+2)$ reactions described above. Later, Mancini and coll. showed that the similar $N$ tosylated nitroindole 1c would lead to a $3: 1$ mixture of regioisomeric dihydrocarbazoles $59 \mathrm{c}$ and $59 \mathrm{~d}$, along with unreacted nitroindole, and that no carbazole formation was observed when decreasing the temperature to $90{ }^{\circ} \mathrm{C}$ for $96 \mathrm{~h},{ }^{39}$ revealing that the complete aromatization is a process favoured by high temperature. The primary nitroindoline cycloadduct $\mathbf{6 1}$ could not be observed in these thermal conditions. This characteristic contrasts with the reactivity observed with other electrophilic indoles (substituted in position 3 by an acetyl, ketoester or ketoamide group for example), for which the cycloaddition reaction led to the formation of a dearomatized of indoline bearing a tetrasubstituted center at the ring junction. ${ }^{39,40}$

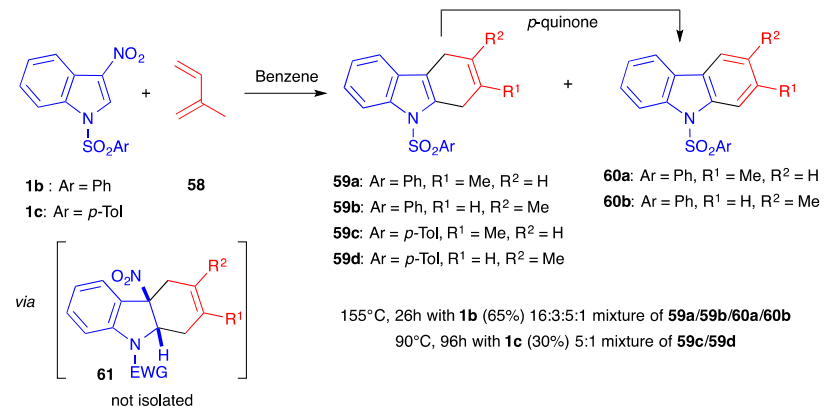

Scheme 23: $(4+2)$ Diels-Alder reaction between 3-nitroindoles 1 and isoprene under thermal activation.

In 1999, Mancini and coll. described the reactivity of 3-nitroindole 1c toward dienamides $62 .{ }^{41}$ Heating the mixture at $90{ }^{\circ} \mathrm{C}$ for 4 days afforded a mixture of the dihydrocarbazole 63 and carbazole 64 in an overall $65 \%$ and $76 \%$ yield, respectively (Scheme 24). The presence of a unique regioisomer 63 suggested a total control of the regiochemistry in the presence of this more polarized diene. Increasing the temperature to $160{ }^{\circ} \mathrm{C}$ led, here again, to the aromatization and carbazole $\mathbf{6 4}$ was the only product isolated in this case. In 2001, the same team reported that lowering the temperature 
to $65{ }^{\circ} \mathrm{C}$ did not allow to isolate the primary nitroindoline cycloadduct, and a similar 4:1 mixture of $63 / 64$, along with unreacted nitroindole $1 \mathrm{c}$ was obtained.

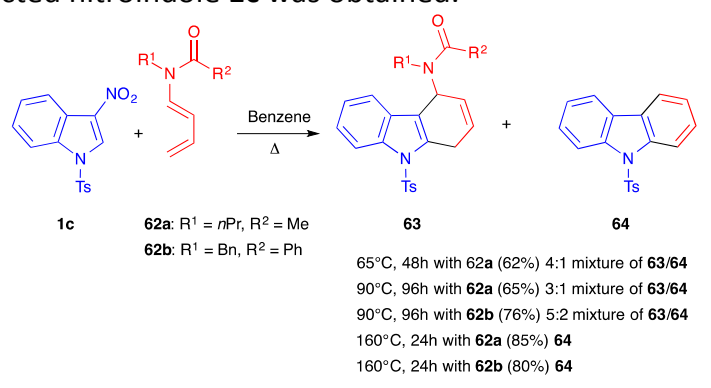

Scheme 24: $(4+2)$ Diels-Alder reaction between 3-nitroindoles $1 \mathrm{c}$ and dienamides 62 under thermal activation.

When the diene bears a trimethylsilyloxy substituent in position 1 , the thermal reaction was shown later to lead to the hydroxycarbazole after $48 \mathrm{~h}$ at $90{ }^{\circ} \mathrm{C}$ in benzene. ${ }^{42}$

In the presence of the 1,3-dioxygenated Danishefsky diene 65, Gribble and coll. showed in 2001 that differently protected

3-nitroindole derivatives could react under thermal conditions (Scheme 25). ${ }^{43}$ Reacting the $N$-phenylsulfonylindole 1a with 65 in refluxing toluene afforded a mixture of the nitroindoline 66a-trans (56\%) along with the re-aromatized carbazol-2-o 67a (35\%). Thus, with this more reactive diene, this showed that the $(4+2)$ dearomatizated cycloadduct was stable and could be isolated, even with a leaving group such as nitro. With the carbamate protected indole $\mathbf{1} \mathbf{b}$, the cycloaddition led to the isolation of carbazolol $67 \mathrm{~b}$ in a good yield of $85 \%$. The same year, Mancini and coll. showed that, in the presence of sulfonylindole $1 \mathrm{c}$, decreasing the temperature to $65^{\circ} \mathrm{C}$ allowed to isolate both the cis and trans diastereomer in an overall $64 \%$ yield $\left(39 \%\right.$ cis-diastereomer, $25 \%$ trans). ${ }^{39}$ A smaller amount of the re-aromatized carbazol-2-ol 67 was also isolated in this case (17\%). This suggested that the cis isomer, which was not isolated in the reaction with $\mathbf{1 a}$, was more sensitive to heating.
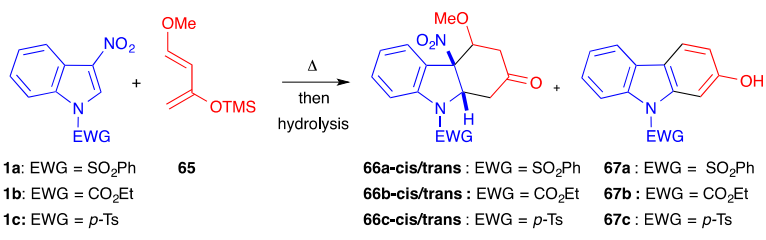

With 1a: Toluene, $110^{\circ} \mathrm{C}$, then $\mathrm{HCl}$ hydrolysis: $66 \mathrm{a}$-trans $(56 \%), 67 \mathrm{a}(35 \%)$

With $1 \mathrm{~b}$ : Toluene, $110^{\circ} \mathrm{C}$, then $\mathrm{HCl}$ hydrolysis: $67 \mathrm{~b}(85 \%)$

With 1c: Benzene, $65^{\circ} \mathrm{C}$ : $\quad 66 \mathrm{c}$-cis $(39 \%)$, 66c-trans $(25 \%), 66 \mathrm{c}(17 \%)$

Scheme 25: $(4+2)$ Diels-Alder reaction between 3-nitroindoles 1c and Danishefsky diene 65 under thermal activation.

These reactions were also performed under microwave irradiation as an alternative to conventional heating. ${ }^{44}$ Gómez and coll. showed, in 2009, that 3-nitroindole 1c reacted with a variety of dienes under $\mathrm{MW}$ irradiation (50 $\left.\mathrm{W}, 100{ }^{\circ} \mathrm{C}\right)$, in solvent free conditions. As shown on Scheme 26 , this activation mode allowed to significantly decrease the reaction time to 30-45 minutes and furnished the aromatized cycloadducts. They were obtained via

$(4+2)$
cycloaddition/elimination/retro-Diels-Alder or or $(4+2)$ cycloaddition/elimination(s) sequences except in the case of cyclopentadiene (68). With this latter reactive diene, the dearomatized nitroindoline 69 was isolated as a single diastereomer, without loss of nitrous acid, in a modest $29 \%$ yield. Computational studies suggest that this stereochemical outcome would arise from an unexpected hetero-Diels-Alder cycloaddition involving the $\mathrm{C}=\mathrm{C}-\mathrm{N}=\mathrm{O}$ electron-poor dienic moiety of the indole and one of the electron-rich $\mathrm{C}=\mathrm{C}$ bond of the cyclopentadiene and would be followed by a $[3,3]-$ sigmatropic shift.

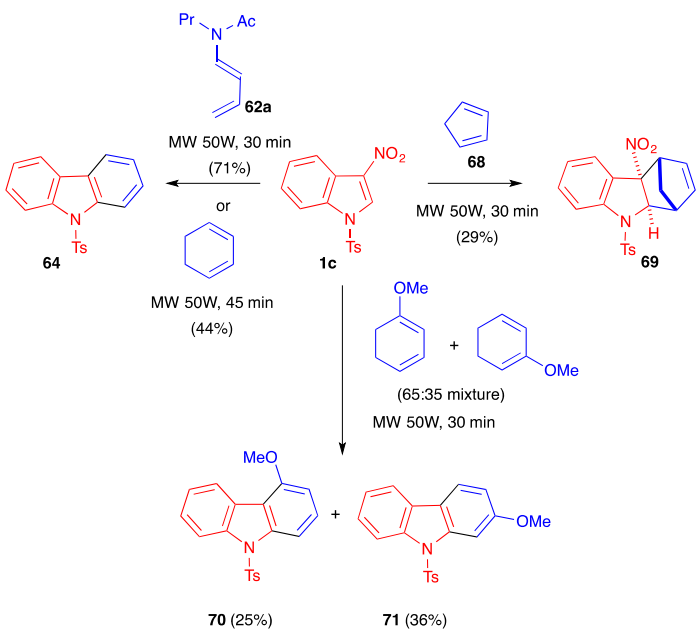

Scheme 26: Reactivity of 3-nitroindole 1c toward different dienes under microwave irradiatior

In 2012, Mancini and co-workers showed that these Diels-Alder reactions could also be performed in protic ionic liquids such as $[\mathrm{HMIM}]\left[\mathrm{BF}_{4}\right] .{ }^{41}$ Thus, nitroindole $1 \mathrm{c}$ reacted with dienes such as isoprene 55, 1-trimethylsilyloxybutadiene 72 or Danishefsky diene 65 , for $24-48 \mathrm{~h}$ at $60^{\circ} \mathrm{C}$ in this neoteric solvent (Scheme 27). After the polar cycloaddition, the carbazole adducts were isolated in good yields. These conditions seemed to favour the elimination reactions occurring after cycloaddition leading to the completely aromatized adducts as sole or highly favoured compounds in all cases.

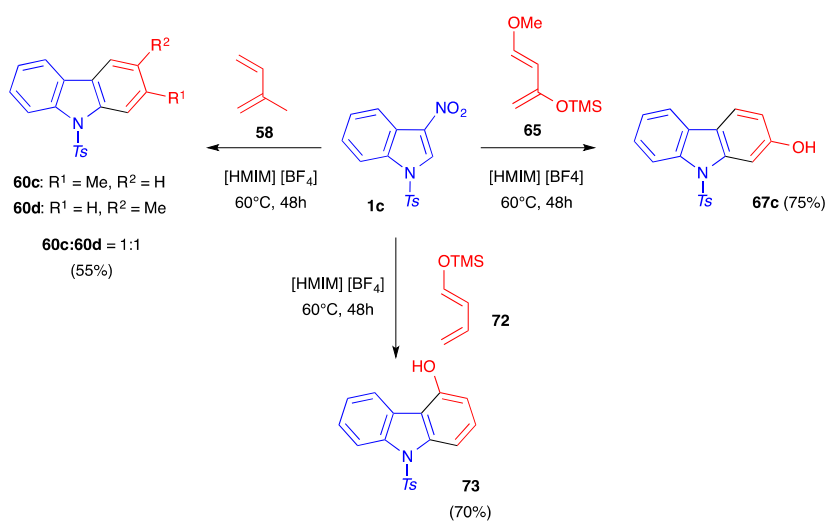

Scheme 27: Reactivity of 3-nitroindole 1c toward different dienes in protic ionic liquid $[\mathrm{HMIM}]\left[\mathrm{BF}_{4}\right]$. 
Compared to thermal conditions, the reactions are favoured in this solvent due to the activation of the dienophilic nitroindole by hydrogen bonding between the oxygen atoms of the nitro group and the acidic hydrogen atom of $[\mathrm{HMIM}]\left[\mathrm{BF}_{4}\right]$. Evaluation of the electrophilicity of the nitroindole by DFT computations indeed showed that if nitroindole 1c is a "strong electrophile" in the electrophilicity scale developed by Domingo and co-workers (global electrophilicity, $\omega=2.25 \mathrm{eV}){ }^{45}$ the activated dienophile 1c[HMIM] $\left[\mathrm{BF}_{4}\right]$ is even more electrophilic $(\omega=3.48 \mathrm{eV}$ in the gas phase, $\omega=2.98 \mathrm{eV}$ when an implicit solvent is considered in the calculations). The regioselectivity observed for these processes is also in line with the calculated local electrophilicities that showed that the $\mathrm{C} 2$ carbon atom of the nitroindole was much more electrophilic than the C3 carbon atom (0.48 vs $0.07 \mathrm{eV}$ for $1 \mathrm{c}$ and 0.75 vs $0.04 \mathrm{eV}$ for 1c[HMIM] $\left.\left[\mathrm{BF}_{4}\right]\right)$.

Diels-Alder reactions are generally characterized by largely negative volume of activation $\left(-25\right.$ to $\left.-45 \mathrm{~cm}^{3} \cdot \mathrm{mol}^{-1}\right)$. Thus, these transformations are often highly accelerated under high pressure. In 2001, taking advantage of this phenomenon, electron-poor indoles bearing electron-withdrawing groups in position 3 were reported to react at room temperature under 12-16 kbar pressures with different electron-rich dienes to yield the corresponding dearomatized primary indolines. ${ }^{46}$ In these conditions, the cycloaddition reaction was promoted while, in contrast, the rearomatization process which involves elimination reaction(s), generally characterized by positive activation volumes, were disfavoured.

Soon after, Mancini and coll. elegantly demonstrated the reactivity of $\mathrm{N}$-sulfonyl-3-nitroindoles $\mathbf{1 c}$ toward various 1,3-dienes under hyperbaric conditions. Interaction of $1 \mathrm{c}$ and isoprene $\mathbf{5 8}$ under a $\mathbf{1 1 . 5}$ kbar pressure, at room temperature, for $24 \mathrm{~h}$ led to the formation of the expected dearomatized cycloadduct 61a, obtained as a single regioisomer, showing the positive effect of high pressure on the transformation (Scheme 28). ${ }^{39}$ The isolated yield however remained low (22\%). Increasing both the temperature to $40{ }^{\circ} \mathrm{C}$ and the reaction time to 3 days enhanced the yield to $75 \%$. In these conditions, traces of the corresponding rearomatized carbazole were observed (5\%), together with some unreacted indole (20\%). 1c could also react with the dienamide 62 a under the same pressure. The cycloaddition led, this time, to a mixture of the desired dearomatized cycloadduct $\mathbf{7 4}$, and the corresponding denitrated compound 63 , obtained in a $1: 2$ ratio, along with unreacted indole (24\%). Satisfyingly, the cycloaddition was also performed with Danishefsky diene 65. With this more reactive diene, a total conversion of the indole $1 \mathbf{c}$ was observed, leading to the nitrocycloadduct $66 \mathrm{c}$ (1:1 d.r.) with no traces of the rearomatized cycloadducts.

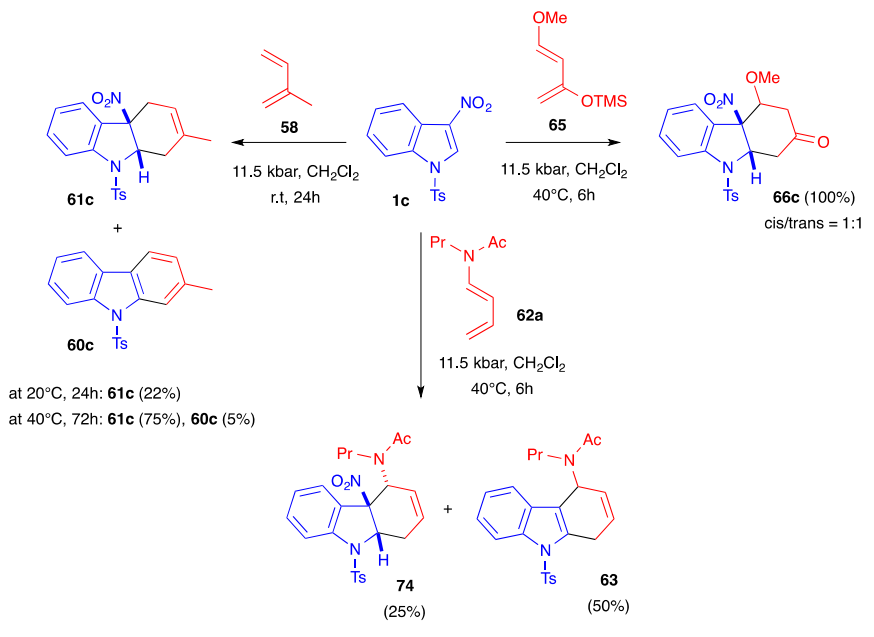

Scheme 28: Dearomative (4+2) cycloadditions of 3-nitroindole 1c with different dienes under high pressure activation.

In 2015, our group reported the dearomative $(4+2)$ cycloaddition of 3-nitroindole $\mathbf{1 c}$ in the presence of Danishefsky diene $\mathbf{6 5}$ at room temperature in the presence of a thiourea organocatalyst. ${ }^{47}$ The achiral Schreiner thiourea catalyst $\mathbf{7 5}$ indeed promoted the Diels-Alder reaction at room temperature. In these mild thermal conditions, no elimination reaction occurred after cycloaddition and the corresponding adducts $66 \mathrm{c}$ (63:37 of trans/cis diastereomer) were isolated in $95 \%$ yield (Scheme 29). Attempts to perform this reaction in an enantioselective manner in the presence of chiral thiourea or squaramide catalysts however led to low enantioselectivities.

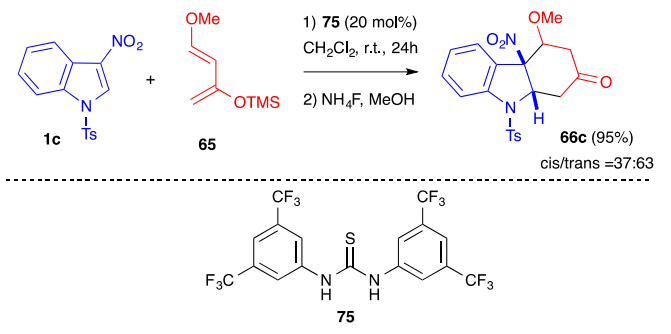

Scheme 29: Dearomative $(4+2)$ cycloadditions of 3-nitroindole 1c with Scheme 29: Dearomative $(4+2)$ cycloadditions
Danishefsky diene 65 under thiourea organocatalysis.

An achievement in the field of enantioselective $(4+2)$ cycloadditions with 3-nitroindoles was the organocatalytic approach reported by Jørgensen and co-workers in 2016 (Scheme 30). ${ }^{48}$ The cycloaddition of 3-nitroindole derivatives 1 with 2,4-dienals 76 was performed in a highly enantioselective fashion in the presence of proline-urea organocatalyst 77. This trienamine pathway showed to be efficient at low temperature and furnished, in the basic conditions of the reaction, chiral dihydrocarbazole $\mathbf{7 8}$ in good yields (up to $\mathbf{8 7 \%}$ ) and enantioselectivies (up to $97 \%$ ee) after nitrous acid elimination. The bifunctionnal organocatalyst brings closer the diene/dienophile substrates, by allowing the formation of the electron-rich trienamine while activating the nitroindole by hydrogen bondings, thus inducing an efficient facial discrimination. 

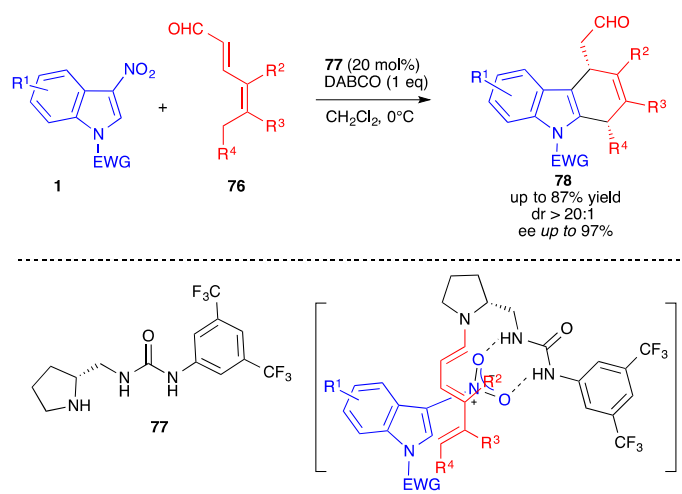

Scheme 30: Organocatalyzed enantioselective (4+2) cycloadditions of 3 nitroindoles with 2,4-dienals 72 .

\section{2. (4+2) Annulations}

(4+2) Dearomative annulations involving 3nitroindoles as electrophiles emerged more recently, taking advantage of the possible addition of nucleophiles at the $\mathrm{C} 2$ position of 3-nitroindoles (Scheme 31). If the nucleophile is a 1,4-zwitterionic dipole, the nitronate intermediate can subsequently cyclize intramolecularly in a $(4+2)$ formal cycloaddition process. The first addition step is the dearomatizing one, often reversible, and the second cyclization step thus shifts the equilibrium toward the formation of the dearomatized cycloadduct. This strategy is compatible with the use of relatively mild nucleophiles for the first determining step.

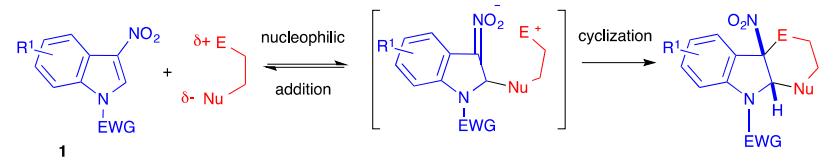

Scheme 31: General dearomative $(4+2)$ annulations of 3-nitroindoles

In 2017, Xu, Yuan and coll. reported the first organocatalyzed reaction of 3-nitroindoles 1 with Nazarov reagents 79, which possess a nucleophilic $\alpha$-carbon and an electronically deficient $\mathrm{C}=\mathrm{C}$ double bond, in presence of the thiourea organocatalyst 80 (Scheme 32 ). ${ }^{49}$ Its bifunctional nature allowed, here again, the activation of the 3-nitroindole 1 by the formation of multiple hydrogen bonds with the amide/thiourea moiety and the simultaneous activation of $\mathbf{7 9}$ through the tertiary amine function of the catalyst. This dual activation was crucial for the reactivity and the stereocontrol. After acylation, the chiral hydrocarbazole skeletons $\mathbf{8 1}$ were obtained in good to high yields with excellent diastereo- and enantio-selectivities.

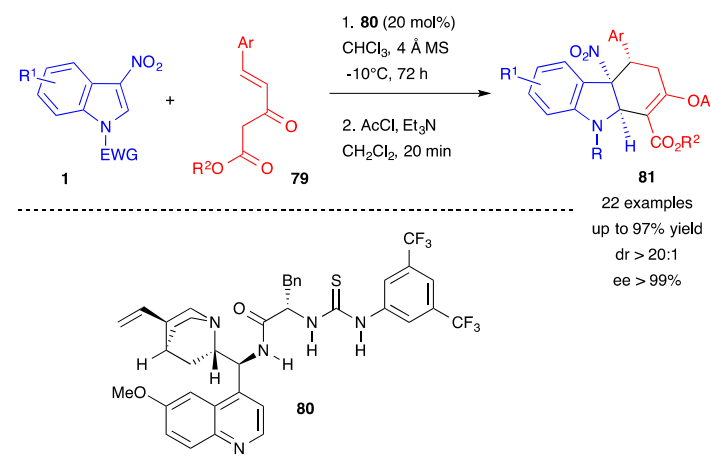

Scheme 32: Enantioselective dearomative $(4+2)$ annulations of 3-nitroindoles with Nazarov reagents 79 .

In 2018, Yang and coll. reported the $(4+2)$ annulation of 3-nitroindoles $\mathbf{1}$ with alkylidene malononitriles $\mathbf{8 2}$ (Scheme 33). ${ }^{50}$ In the presence of triethylamine, carbazol-4-amine derivatives 83 were obtained via a four-steps sequence involving (i) vinylogous Michael addition, (ii) cyclization, (iii) isomerization, (iv) nitrous acid elimination. This reaction was recently extended to different $\alpha, \alpha$-dicyanoalkenes $82 .{ }^{51}$

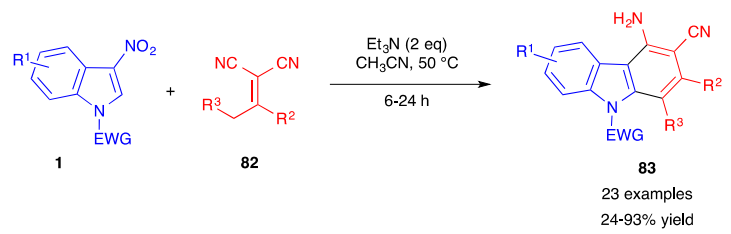

Scheme 33: $(4+2)$ annulations of 3-nitroindoles with alkylidene malononitriles Sche
82.

In 2019, Ding, Hou and coll. developed a palladiumcatalyzed asymmetric decarboxylative $(4+2)$ annulation of 3 nitroindoles 1 with benzoxazinanones 84a (Scheme 34). ${ }^{52}$ In the presence of $\mathrm{Pd}_{2} \mathrm{dba}_{3} \cdot \mathrm{CHCl}_{3}(2.5 \mathrm{~mol} \%)$ and a chiral SIOCPhox ligand 85 (5 mol\%), a series of chiral dearomatized tetrahydro-5 $\mathrm{H}$-indolo[2,3-b]quinolines 86a were obtained in high yields, up to $97 \%$, and good to excellent stereoselectivities (dr>95:5, ee=79-95\%). $N$-tosyl protected vinyl benzoxazinanones $\mathbf{8 4}$ were required and no reaction took place when replacing the tosyl group with a proton, a nosyl or an acetyl group. The authors proposed a transition state involving a dual role of the catalyst, allowing the formation of the $\pi$-allylic 1,4-dipole and activating the nitro group of the indole with the phenol hydroxyl group of the ligand to account for the observed stereoselectivities. 

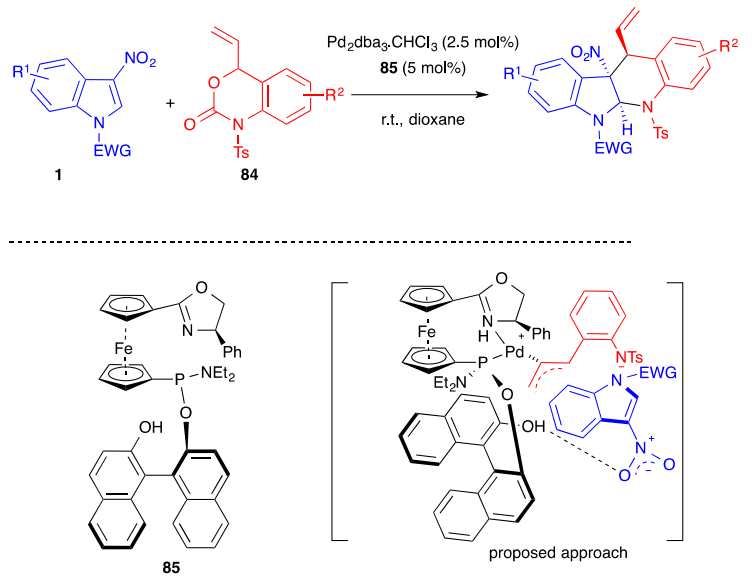

Scheme 34: Enantioselective palladdium catalyzed decarboxylative (4+2) annulations of 3-nitroindoles with $\mathrm{N}$-tosyl vinyl benzoxazinanones $\mathbf{8 4}$.

Hyland and co-workers demonstrated recently that the same reaction was also possible in the presence of unprotected vinyl benzoxazinanones $\mathbf{8 7}$, using higher catalyst loading $\mathrm{Pd}_{2} \mathrm{dba}_{3} \cdot \mathrm{CHCl}_{3}(7.5 \mathrm{~mol} \%)$ and ligand (15 mol\%) (Scheme 35$).^{53}$ In a diastereoselective version of the process, the reaction could be promoted by the simple and air-stable phenanthroline ligand. Excellent yields and trans diastereoselectivities were reported with this catalytic system, even in the absence of any electrophilic activation of the nitro group. To account for this trans preference, the authors proposed a reversible nucleophilic attack at the $\mathrm{C} 2$ position of the indole to generate a nitronate, which would undergo a ring-closure via a favoured boat-like transition state. Noteworthy, $\mathrm{N}$-sulfonylated nitroindoles $\mathbf{1}$ were required for this process as $\mathrm{N}$-carbonylated substrates proved inert or led to decomposition. In addition, C3-substituted acetyl, cyano, and methyl ester indoles failed in the reaction, showing, here again, the importance of the nitro group in position 3 for enhancing the electrophilicity of the indole ring. When performed in the presence of a chiral phosphinooxazoline ligand $\mathbf{8 8}$, high yield and ee for the trans diastereomer ( $>99 \%$ ee) were reported. However, the dr was significantly impacted (Scheme 35).
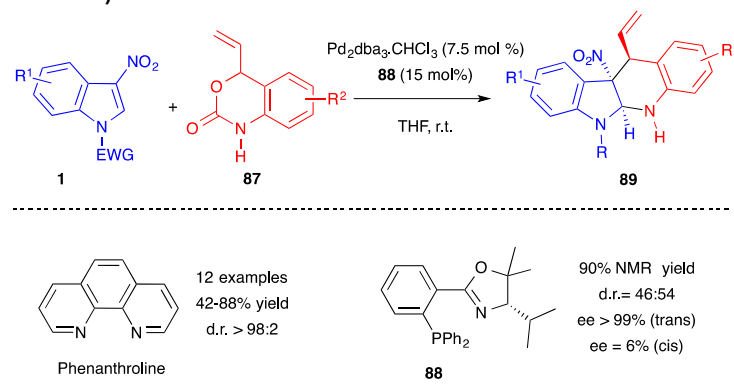

Scheme 35: Palladium catalyzed decarboxylative $(4+2)$ annulations of $3-$ nitroindoles with unprotected vinyl benzoxazinanones 87 .

In 2019 , the dearomative $(4+2)$ annulation of 3 nitroindoles 1 in the presence of enolizable vinylketones 90 was reported in basic conditions, at low temperatures (Scheme $36) .{ }^{54}$ The in situ generated lithium enolates add to the C2position of the nitroindoles 1 . Then, depending on the substrates, trans 1,4-adducts 91 or, most of the time, in situ cyclized adducts 92 were isolated in good yields. This method constitutes an alternative to the classical Diels-Alder cycloaddition performed in the presence of 2-silyloxy-1,3dienes, such as Danishefsky diene, for which the re-aromatized carbazolols $\mathbf{6 4}$ are often isolated (vide supra).

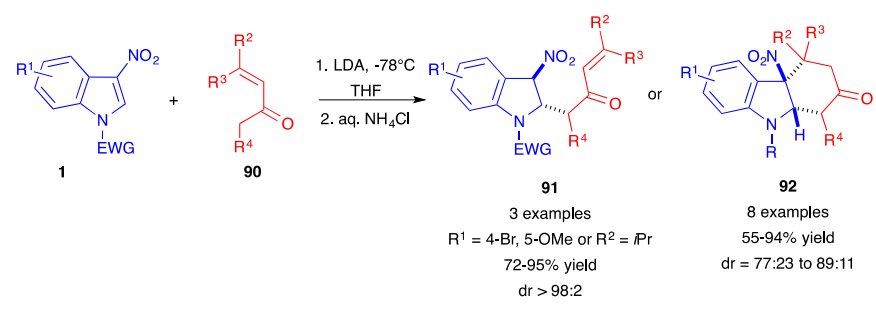

Scheme 36: Dearomative $(4+2)$ annulations of 3-nitroindoles with enolizable vinyl ketones 90.

Guo and coll. recently reported the phosphinecatalyzed enantioselective (4+2) annulation of 3-nitroindoles 1 with allenoates $\mathbf{9 3}$ at room temperature, in the presence of a chiral phosphine catalyst 94 (Scheme 37$).{ }^{55}$ Such a process generally leads to the generation of tetrahydrocyclopenta[b]indoline 47 , according to a $(3+2) \mathrm{Lu}$ annulation (vide supra, Scheme 17). With allenoates 93, bearing an alpha substituent, most of the time benzylic, a different and complementary pathway was observed. The dipole A generated after nucleophilic addition of the phosphine on the allenoate reacted with the electrophilic indole through its less sterically hindered $\gamma$-position, this time, leading to a nitronate zwitterion B. Migration of the double bond, followed by intramolecular cyclization would lead to $\mathbf{D}$, which would release the catalyst and furnish the formal $(4+2)$ cycloadduct $\mathbf{E}$. In the reported reaction conditions, rearomatization of the 5-membered ring by loss of nitrous acid would then afford the isolated dihydrocarbazole 95 in good yields and enantioselectivities.

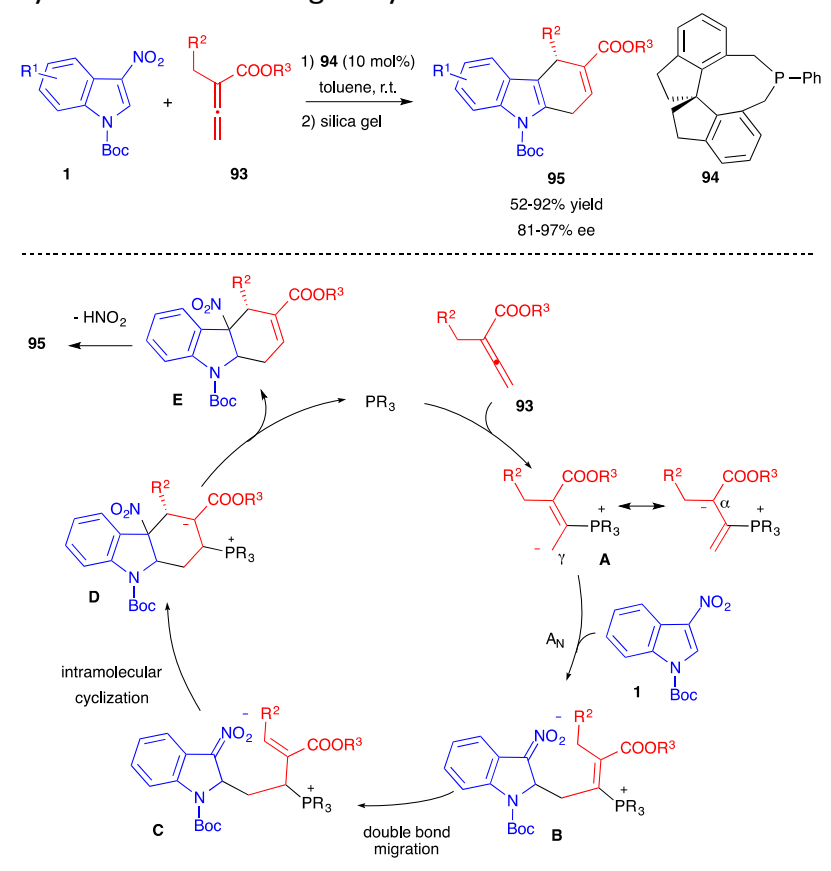


In 2020, Huang, Li and coll. reported a novel type of dearomative (4+2)-annulation of 3-nitroindoles 1 with $\beta$ substituted crotonaldehydes 96 (Scheme 38). ${ }^{56}$ Under an oxidative $\mathrm{N}$-heterocyclic carbene (NHC) catalyzed process, dearomatized hydrocarbazolones $\mathbf{9 7}$ were obtained in good yields. The use of a chiral NHC catalyst allowed to perform an enantioselective version of this reaction, with ee up to $74 \%$. This was however detrimental to the isolated yield (18\%).
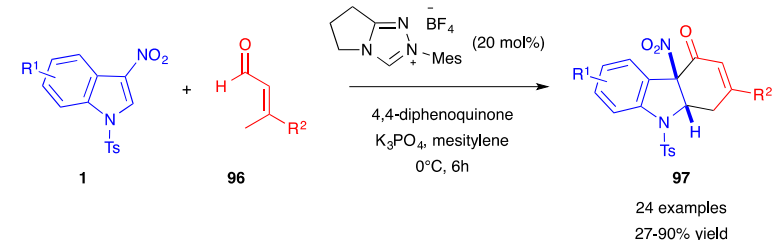

Scheme 38: Oxidative NHC-catalyzed (4+2) annulation of 3-nitroindoles 1 with $\beta$ substituted crotonaldehydes $\mathbf{9 6}$.

\section{4. $(4+2) /(3+2)$ cycloaddition reactions}

The cycloadditions/annulations described so far rely on the electrophilic character of the $\mathrm{C} 2=\mathrm{C} 3$ double bond of the 3 -nitroindole derivatives. Based on the reactivity of the $\mathrm{C} 2=\mathrm{C} 3$ $\mathrm{N}=\mathrm{O}$ system as an electron-poor hetero-diene, ${ }^{57}$ in 2007 , the first multicomponent domino $(4+2) /(3+2)$ cycloaddition process was reported in the presence of $\mathrm{N}$-tosyl-3-nitroindoles 1c. Performed in the presence of an electron-rich vinyl ether dienophile $\mathbf{9 8}$ and an electron-poor acrylate dipolarophile 99, the reaction led to the formation of a nitrosoketal $\mathbf{1 0 0}$ in one operation (Scheme 39). ${ }^{58}$ Under reductive conditions, 100 could be converted into $\mathbf{1 0 1}$ in high yields, through (i) $\mathrm{N}-\mathrm{O}$ hydrogenolyses, (ii) formation of an imine and its reduction into pyrrolidine, (iii) lactamization.

In an attempt to develop an enantioselective version of this reaction, it was performed in the presence of different chiral thioureas or sulfonamides, but the enantioselectivities remained low (up to $30 \%$ ee). ${ }^{47}$
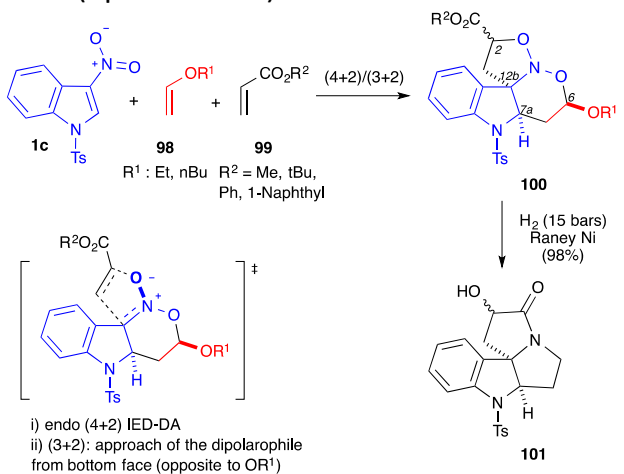

Scheme 39: Domino $(4+2) /(3+2)$ cycloaddition 3-nitroindole 1c with vinylethers 98 and acrylates 99 .

In this reaction, 4 stereocenters were created and 8 couples of diastereomers potentially obtained. High pressure conditions proved to lead to the best distereoselectivity (Table
3, compare entries 1-4). The two diastereomers obtained in these conditions were shown to differ in the relative positions of the centre alpha to the ester group, the result of an endo $(4+2)$ inverse electron demand hetero-Diels-Alder reaction (relative stereochemistry of $\mathrm{C}_{7 a}$ and $\mathrm{C}_{6}$ ), a face selective $(3+2)$ cycloaddition (dipolarophile from the face opposite to $\mathrm{OR}^{1}$, relative stereochemistry of $\mathrm{C}_{12 \mathrm{~b}}$ ), while the endo vs exo approach of the dipolarophile is poorly controlled (two diastereomers differing in the relative stereochemistry of $\mathrm{C}_{2}$ ). Switching to an acrylate bearing a more hindered aromatic moiety led to a higher diastereoselectivity (Table 3, entry 7).

Table 3: Reactions of 3-nitroindoles with ethyl vinylether 98a $\left(R^{1}=E t\right)$ and Table 3: React
acrylates 99

\begin{tabular}{|c|c|c|c|c|}
\hline Entry & Conditions & $\mathrm{R}^{2}$ & $\begin{array}{c}\text { Yield } \\
(\mathbf{1 0 0 )}(\%)\end{array}$ & $\mathrm{dr}$ \\
\hline 1 & $\mathrm{CH}_{2} \mathrm{Cl}_{2}$, r.t., $168 \mathrm{~h}$ & Me & 20 & $50 / 50 / 0 / 0$ \\
\hline 2 & Tol., $110^{\circ} \mathrm{C}, 60 \mathrm{~h}$ & $\mathrm{Me}$ & 83 & $45 / 45 / 5 / 5$ \\
\hline 3 & $\mathrm{MW}(120 \mathrm{~W}), 130^{\circ} \mathrm{C}, 1 \mathrm{~h}$ & Me & 75 & $35 / 35 / 15 / 15$ \\
\hline 4 & HP (12kbar), r.t., $24 \mathrm{~h}$ & Me & 83 & $55 / 45 / 0 / 0$ \\
\hline 5 & HP (12kbar), r.t., $24 \mathrm{~h}$ & $\mathrm{tBu}$ & 83 & $60 / 40 / 0 / 0$ \\
\hline 6 & HP (12kbar), r.t., $24 \mathrm{~h}$ & $\mathrm{Ph}$ & 92 & $66 / 34 / 0 / 0$ \\
\hline 7 & HP (12kbar), r.t., $24 \mathrm{~h}$ & 1-naphthyl & 99 & $78 / 22 / 0 / 0$ \\
\hline
\end{tabular}

DFT calculations, reported on these multicomponent domino $(4+2) /(3+2)$ cycloadditions of 3-nitroindoles confirmed that, the endo approach with the regiochemistry observed experimentally was indeed the most favourable pathway for the primary $(4+2)$ cycloaddition reaction. ${ }^{59}$ The 3-nitroindole reacted through its LUMO as an electron-poor heterodiene in a concerted though asynchronous inverse demand hetero-DielsAlder. The electronic rearrangements observed during this step were in line with the expected pathway and, for this first cycloaddition process, the FMO model provided perfectly reliable predictions (Scheme 40).

The results computed for the subsequent $(3+2)$ cycloaddition reaction were also in line with the experimental results, with a more favoured approach of the dipolarophile from the face opposite to the alkoxy group of the intermediate. A small endo and exo difference also accounted for the poor diastereoselectivity experimentally observed. During the second $(3+2)$ cycloaddition step, however, unexpected electronic rearrangements were observed. Even if electrondeficient acrylate appeared to react in preference to electronrich vinyl ether with the intermediate nitronate, the calculations demonstrated that the electron-poor dipolarophile provided the electrons to the electron-rich dipole (Scheme 40 , arrow b for the $(3+2)$ step).

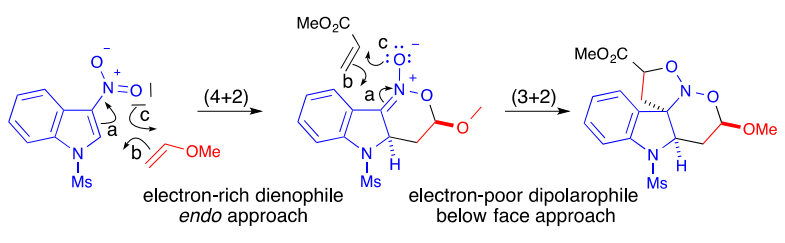




\section{Reactions with other nucleophiles}

\subsection{Nucleophilic addition reactions}

The electrophilicity of 3-nitroindole derivatives allows the addition of different types of nucleophiles to the $\mathrm{C2}$ position of the heterocycle, leading to a nitronate intermediate. The addition can be reversible and leads to different types of adducts, depending on the quenching of the intermediate. When reacted with ethyl isocyanoacetate 37 a in the presence of an organic base such as DBU, it has been shown above that 3-nitroindoles 1 protected as $\mathrm{N}$-benzyl, $\mathrm{N}$ pyridyl or N-ethoxycarbonyl compounds underwent a BartonZard reaction, by conjugate nucleophilic addition of the enolate anion on the nitroindole substrate, followed by intramolecular 5-endo-dig cyclization of the intermediate nitronate on the isocyanide (vide supra, Scheme 14 ). ${ }^{25}$ When more electron-withdrawing groups such as phenylsulfonyl were activating the indole ring, an abnormal regioselectivity was observed for this reaction, leading to a ring opening/rearrangement and a regioisomeric cycloadduct 102 (Scheme 41 ). ${ }^{26}$ The mechanism proposed by Gribble and coll. to account for this unexpected regioselectivity involved first the expected Michael addition of the enolate anion resulting from the deprotonation of the isocyanide on the $\mathrm{C} 2$ position of the nitroindole. Then, an expected ring opening occurs would occur. After prototropy, the nitronate anion would add on the isocyanide to form the 5 membered ring. After prototropy, ring closure of the central ring and concomitant elimination of nitrite, a final isomerisation would lead to the isolated compound 102.

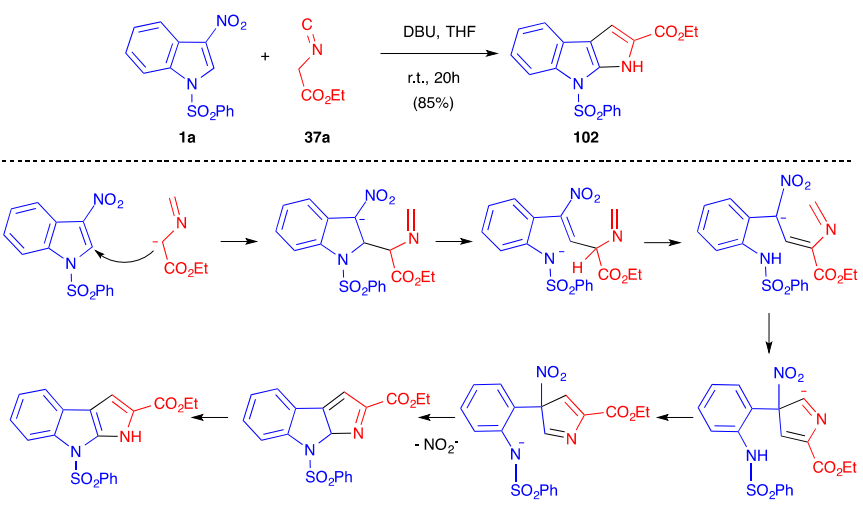

Scheme 41: Abnormal Barton-Zard reaction between indole 1a and isocyanide $37 a$.

Later in 2003, Gribble disclosed several nucleophilic additions of enolates to 3-nitroindole 1a. Thus, the "simple" addition of the anion on the $\mathrm{C} 2$ position of the indole results, after hydrolysis, to the dearomatized indolines 103 (Scheme 42). ${ }^{60}$ Thus, the use of deprotonated diethyl malonate or cyclohexanone led to the formation of the Michael-type nitronate adduct, which furnished selectively the trans indoline after hydrolysis. Similarly, addition of a vinyl Grignard reagent led to the trans adduct $\mathbf{1 0 3 c}$

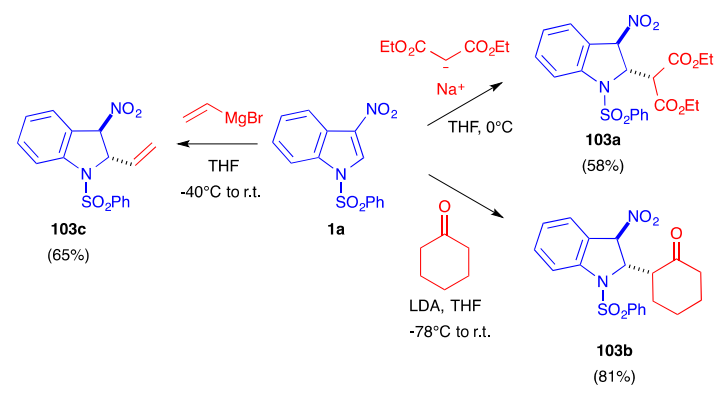

Scheme 42: Michael addition of enolates and vinyl Grignard reagents on nitroindole 1a.

The use of alkyl Grignard reagents led to the same Michael adducts 103, however with a small amount of the ketones 104, resulting from the Nef reaction (Scheme 43). Rearomatization of $\mathbf{1 0 3}$ into $\mathbf{1 0 5}$ could easily be performed in the presence of $\mathrm{Pd} / \mathrm{C}$.

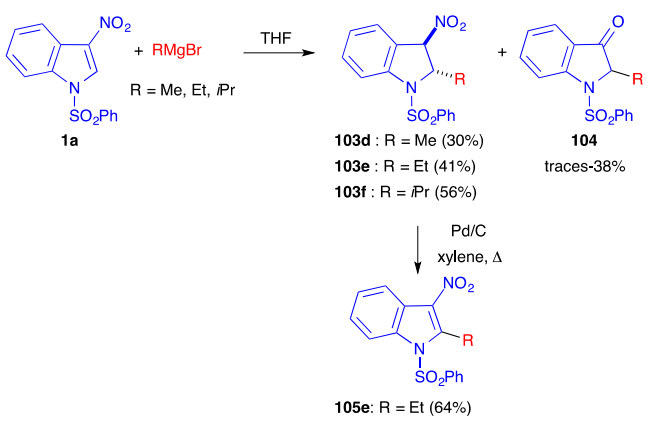

Scheme 43: Nucleophilic addition of alkyl Grignard reagents on nitroindole 1a.

In 2010, the same group reported the nucleophilic addition of (hetero)aryllithiated compounds to 3-nitroindole 1a. In most cases, the reaction led to the $\mathrm{N}$-deprotected adduct 107 in good yields (Scheme 44). ${ }^{61}$ The authors proposed a mechanism involving the nucleophilic addition of the lithium compound on the C2 position of the indole, followed by an elimination of the sulfinate anion and prototropy. In one case only, involving a 2-lithioindolic nucleophile, the corresponding trans indoline 103 was isolated.

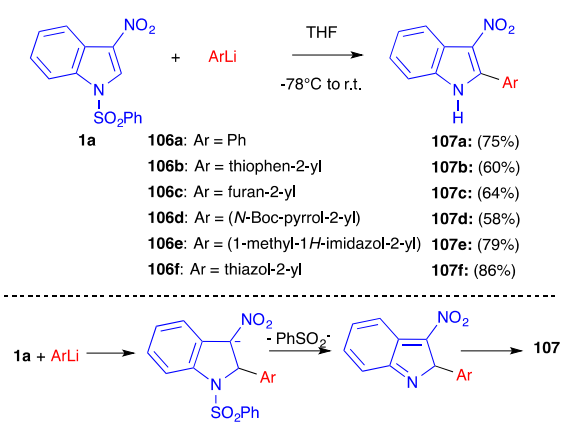


Scheme 44: Nucleophilic addition of organolithium nucleophiles 106 on nitroindole 1a.

5.2. Nucleophilic additions: the special case of enamines

More recently, the addition of enamines on nitroindoles 1 has been studied. In 2016, the stoichiometric addition of 4-(cyclohex-1-en-1-yl)morpholine 108 on 1c, in mild anhydrous conditions, was reported to lead to the formation of the unexpected dearomatized indoline 109, as a single regioisomer and diastereomer (Scheme 45). ${ }^{62}$ It was isolated in an excellent $95 \%$ isolated yield, even on a $10 \mathrm{~g}$ scale. This formal ene adduct 109 would be formed by nucleophilic addition of the enamine on the $\mathrm{C} 2$ position of the nitroindole followed by selective proton abstraction in the conditions of the reaction. The reaction proved to be reversible in solution and the ene adduct $\mathbf{1 0 9}$ was sensitive to water. It was efficiently isolated in this case thanks to its highly crystalline character. When compared to the addition of vinylethers that required high temperatures or high pressure conditions, the addition of enamines is much easier, and reflects the much higher nucleophilicity of enamines. DFT computations in this field suggested that the greatest difference between these oxygenated and nitrogenated nucleophiles would come from the much higher stability of the zwitterionic nitronate intermediate resulting from the addition (iminium vs oxonium). ${ }^{63}$

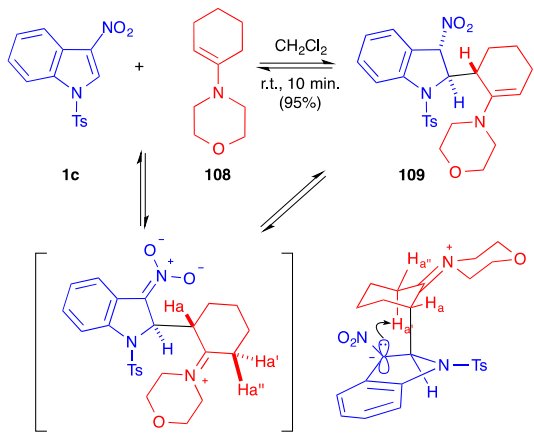

Scheme 45: Dearomatizing formal ene reaction on nitroindole 1c.

In 2017, John and coll. studied the addition of in situ generated enamines toward nitroindoles. ${ }^{64}$ They showed that reacting the nitroindole $\mathbf{1 c}$ with an enolizable ketone $\mathbf{1 1 0}$ and a primary amine 111 , in toluene at $60-110{ }^{\circ} \mathrm{C}$ in the presence of $4 \AA \mathrm{MS}$ led to the formation of aromatized pyrrolo[3,2b]indoles 112 in good yields (Scheme 46). In this case, the involvement of a primary amine would lead to the formation of an imine, in equilibrium with the enamine 113. The authors proposed a mechanism involving first the nucleophilic addition of the enamine to the $C 2$ position of the indole derivative, as previously observed. In this case, however, the iminium proton could be trapped by one of the nitronate oxygen atom. A second enamine addition would then allow for the fivemembered ring closure. This latter would then aromatize by elimination of hyponitrous acid and water, generating 112.
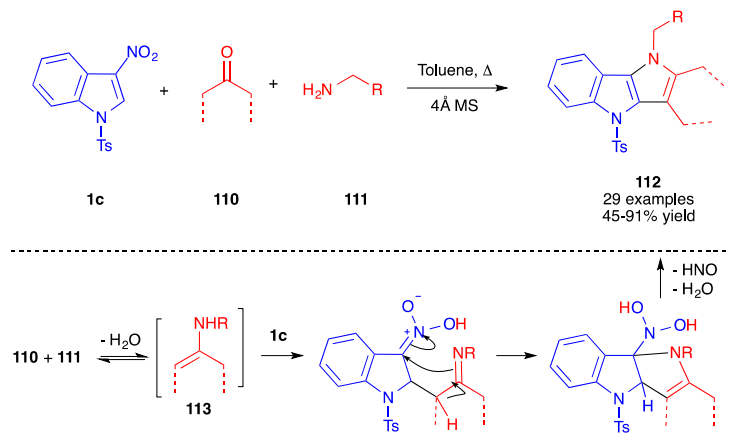

Scheme 46: Multicomponent reaction involving nitroindole $1 \mathrm{c}$ to generate pyrrolo-indoles 112.

Soon after, the same authors reported an extended version of the methodology toward the synthesis of indolo[3,2b] indoles 114 (Scheme 47). ${ }^{65}$ In this case, in the presence of cyclic ketones, the intermediate pyrrolo[3,2b]indoles, formed after $12 \mathrm{~h}$ in toluene at $60{ }^{\circ} \mathrm{C}$, were oxidized in situ by addition of chloranil as oxidant. The corresponding fully aromatized compounds $\mathbf{1 1 4}$ were isolated in good overall yields.

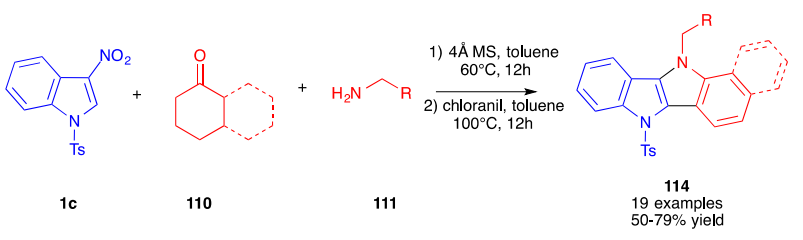

Scheme 47: One-pot generation of indolo-indoles 111 from nitroindole 1c.

\subsection{Nucleophilic aromatic substitution reactions}

In 2006, Gribble and Roy described an efficient $\mathrm{S}_{\mathrm{N}} \mathrm{Ar}$ reaction involving secondary amines and an activated 2 -iodo3-nitroindole 115 (Scheme 48). ${ }^{66}$ The reaction was performed in mild conditions, with a range of secondary amines 116, affording the corresponding 2-amino-3-nitroindole $\mathbf{1 1 7}$ in very good yields (76-96\%). With the less nucleophilic primary cyclohexylamine, the yield dropped.

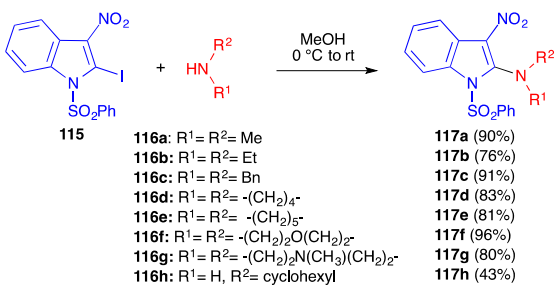

Scheme 48: Nucleophilic aromatic substitution between 2-iodo-3-nitroindole 99 and amines 100 .

\section{Conclusions}

3-Nitroindoles 1 exhibit an unexpected, albeit remarkable, electrophilic reactivity toward different electron-rich species, notably in dearomative cycloaddition and annulation reactions. This peculiarity is directly related to the $\mathrm{C} 2=\mathrm{C} 3$ 
double bond of nitroindoles that can behave either as a dipolarophile, a dienophile or a Michael acceptor in dearomatizing $(3+2),(4+2)$ cycloadditions or nucleophilic addition reactions. Complementarily, the heterodienic character of the $\mathrm{C} 2=\mathrm{C} 3-\mathrm{N}=\mathrm{O}$ system of 3-nitroindoles explains their reactivity in multicomponent tandem $(4+2) /(3+2)$ cycloadditions.

The reported cycloadditions can be concerted; the corresponding transformations generally involve a highly asynchronous transition state with a smaller forming bond at the C2 position. The limit of this concerted asynchronous mechanism is encountered in many other cases with stepwise processes, in which the first step involves a reversible dearomatizing nucleophilic addition, and the nitronate intermediate is then trapped intramolecularly in a formal cycloaddition process.

Recent developments of these reactions include efficient enantioselective strategies, often taking advantage of bifunctional catalysis, activating the electrophilicity of the indole moiety by hydrogen bonding with the nitro group, for instance with thiourea containing catalysts, and the reacting nucleophilic species formed/activated meanwhile, both linked by a chiral tether.

All these transformations recently reported on the electrophilic 3-nitroindoles underline how this heteroaromatic motif has become a model substrate for electron-poor aromatic compounds in dearomatization strategies.

The reported transformations have led to the expedient synthesis of differently functionalized indolines, which often retain a tetrasubstituted centre at the cis junction of the heterocycle, a feature often retained in natural products of interest. These new structures themselves are potentially relevant compounds for biological or catalytic applications. In addition, after dearomatization, even if the nitro group is still on a benzylic position, it can be simply reduced into the corresponding amino group, using for instance the $\mathrm{TMSCl} / \mathrm{Zn}$ system, in most cases. Denitration reactions can also be easily performed, notably through radical denitration strategies. Rearomatization of the 5-membered cycle, by elimination of nitrous acid, is also an easy process. All these transformations and post-functionalizations of the 3 -nitroindole motif thus make this compound a good scaffold for diversity oriented synthesis (Scheme 49).

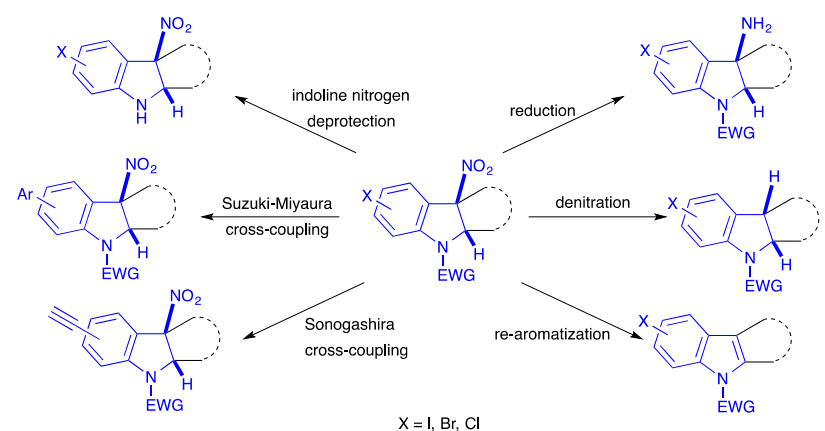

Scheme 49: Representative post-functionalizations of the nitroindolines obtained through dearomatizations of 3-nitroindoles.

\section{Acknowledgements}

Financial supports from the Agence Nationale pour la Recherche ("ArDCo", ANR-17-CE07-0050), the European France-(Manche)-England cross-border cooperation program INTERREG V A "LABFACT" and "SMARTT", co-financed by ERDF, and Janssen R\&D are aknowledged. The authors also thank Normandie Université, CNRS, INSA Rouen, Tremplin Carnot I2C, Labex SYNORG (ANR-11-LABX-0029) and the Région Normandie.

\section{Notes and references}

1 I. G. Sonsona, Synlett, 2015, 26, 2325-2326.

2 J. M. Saya, E. Ruijter and R. V. A. Orru, Chem. Eur. J., 2019, 25, 8916-8935.

3 A. Cerveri and M. Bandini, Chin. J. Chem., 2020, 38, 287294.

4 G. W. Gribble, E. T. Pelkey and F. L. Switzer, Synlett, 1998, 1998, 1061-1062.

5 G. W. Gribble, E. T. Pelkey, W. M. Simon and H. A. Trujillo, Tetrahedron, 2000, 56, 10133-10140.

6 S. Roy, T. L. S. Kishbaugh, J. P. Jasinski and G. W. Gribble, Tetrahedron Letters, 2007, 48, 1313-1316.

7 S. Lee, I. Chataigner and S. R. Piettre, Angew. Chem. Int. Ed., 2011, 50, 472-476.

8 S. Lee, S. Diab, P. Queval, M. Sebban, I. Chataigner and S. R. Piettre, Chem. Eur. J., 2013, 19, 7181-7192.

9 M. Manneveau, S. Tanii, F. Gens, J. Legros and I. Chataigner, Org. Biomol. Chem., 2020, 18, 3481-3486.

10 T. Thierry, C. Lebargy, E. Pfund and T. Lequeux, The Journal of Organic Chemistry, 2019, 84, 5877-5885.

11 A. Awata and T. Arai, Angewandte Chemie International Edition, 2014, 53, 10462-10465.

12 A. L. Gerten and L. M. Stanley, Org. Chem. Front., 2016, 3, $339-343$

13 X. Liu, D. Yang, K. Wang, J. Zhang and R. Wang, Green Chem., 2017, 19, 82-87.

14 B. M. Trost and G. Mata, Acc. Chem. Res., 2020, acs.accounts.0c00152.

15 B. M. Trost, V. Ehmke, B. M. O'Keefe and D. A. Bringley, J. 
Am. Chem. Soc., 2014, 136, 8213-8216.

16 T. Vivekanand, B. Satpathi, S. K. Bankar and S. S. V. Ramasastry, RSC Adv., 2018, 8, 18576-18588.

17 D. J. Rivinoja, Y. S. Gee, M. G. Gardiner, J. H. Ryan and C. J. T. Hyland, ACS Catal., 2016, 1053-1056.

18 J.-J. Suo, W. Liu, J. Du, C.-H. Ding and X.-L. Hou, Chemistry - An Asian Journal, 2018, 13, 959-963.

19 M. Laugeois, J. Ling, C. Férard, V. Michelet, V. Ratovelomanana-Vidal and M. R. Vitale, Organic Letters, 2017, 19, 2266-2269.

20 Y. S. Gee, D. J. Rivinoja, S. M. Wales, M. G. Gardiner, J. H. Ryan and C. J. T. Hyland, The Journal of Organic Chemistry, , DOI:10.1021/acs.joc.7b02624.

21 M. Sun, Z.-Q. Zhu, L. Gu, X. Wan, G.-J. Mei and F. Shi, The Journal of Organic Chemistry, , DOI:10.1021/acs.joc.7b03259.

22 J.-Q. Zhang, F. Tong, B.-B. Sun, W.-T. Fan, J.-B. Chen, D. Hu and X.-W. Wang, The Journal of Organic Chemistry, 2018, 83, 28822891.

23 Q. Cheng, F. Zhang, Y. Cai, Y.-L. Guo and S.-L. You, Angewandte Chemie International Edition, 2018, 57, 2134-2138.

24 J. Ling, D. Mara, B. Roure, M. Laugeois and M. R. Vitale, J. Org. Chem., 2020, acs.joc.9b03459.

25

E. T. Pelkey, Chem. Commun., 1997, 1873.

26 E. T. Pelkey, L. Chang and G. W. Gribble, Chem. Commun., 1996, 1909-1910.

27 J.-Q. Zhao, M.-Q. Zhou, Z.-J. Wu, Z.-H. Wang, D.-F. Yue, X.Y. Xu, X.-M. Zhang and W.-C. Yuan, Organic Letters, 2015, 17, 22382241.

28 J.-Q. Zhao, Z.-J. Wu, M.-Q. Zhou, X.-Y. Xu, X.-M. Zhang and W.-C. Yuan, Org. Lett., 2015, 17, 5020-5023.

29 X.-M. Chen, C.-W. Lei, D.-F. Yue, J.-Q. Zhao, Z.-H. Wang, X.M. Zhang, X.-Y. Xu and W.-C. Yuan, Organic Letters, 2019, acs.orglett.9b01688.

30 H. Wang, J. Zhang, Y. Tu and J. Zhang, Angewandte Chemie International Edition, 2019, 58, 5422-5426.

31 K. Li, T. P. Gonçalves, K.-W. Huang and Y. Lu, Angewandte Chemie International Edition, 2019, 58, 5427-5431.

32 L.-W. Jin, F. Jiang, K.-W. Chen, B.-X. Du, G.-J. Mei and F. Shi, Organic \& Biomolecular Chemistry, 2019, 17, 3894-3901.

K. Liu, G. Wang, S.-J. Cheng, W.-F. Jiang, C. He and Z.-S. Ye,
Tetrahedron Letters, 2019, 60, 1885-1890.

34 A. Cerveri, O. N. Faza, C. S. López, S. Grilli, M. Monari and M. Bandini, The Journal of Organic Chemistry, 2019, 84, 6347-6355.

35 L. Birbaum, L. Gillard, H. Gérard, H. Oulyadi, G. Vincent, X. Moreau, M. De Paolis and I. Chataigner, Chemistry - A European Journal, 2019, 25, 13688-13693.

36 I. Chataigner, C. Panel, H. Gérard and S. R. Piettre, Chemical Communications, 2007, 3288.

37 M.-S. Mei, Y.-H. Wang, Q. Hu, Q.-H. Li, D.-Y. Shi, D. Gao, G. Ge, G.-Q. Lin and P. Tian, Chem. Commun., 2020, 56, 10718-10721.

38 Ernest. Wenkert, P. D. R. Moeller and S. R. Piettre, J. Am. Chem. Soc., 1988, 110, 7188-7194.

39 B. Biolatto, M. Kneeteman, E. Paredes and P. M. E. Mancini, The Journal of Organic Chemistry, 2001, 66, 3906-3912.

40 A. Chrétien, I. Chataigner, N. L'Hélia and S. R. Piettre, The Journal of Organic Chemistry, 2003, 68, 7990-8002.

41 B. Biolatto, M. Kneeteman and P. Mancini, Tetrahedron Letters, 1999, 40, 3343-3346.

42 C. D. D. Rosa, C. M. Ormachea, A. S. Sonzogni, M. N. Kneeteman, L. R. Domingo and P. M. E. Mancini, LOC, 2012, 9, 691695.

43 T. L. S. Kishbaugh and G. W. Gribble, Tetrahedron Letters, 2001, 42, 4783-4785.

44 M. Victoria Gómez, A. I. Aranda, A. Moreno, F. P. Cossío, A. de Cózar, Á. Díaz-Ortiz, A. de la Hoz and P. Prieto, Tetrahedron, 2009, 65, 5328-5336.

45 L. R. Domingo, M. J. Aurell, P. Pérez and R. Contreras, Tetrahedron, 2002, 58, 4417-4423.

46 I. Chataigner, E. Hess, L. Toupet and S. R. Piettre, Organic Letters, 2001, 3, 515-518.

47 M. Andreini, M. De Paolis and I. Chataigner, Catalysis Communications, 2015, 63, 15-20.

48 Y. Li, F. Tur, R. P. Nielsen, H. Jiang, F. Jensen and K. A. Jørgensen, Angew. Chem. Int. Ed., 2016, 55, 1020-1024.

49 D.-F. Yue, J.-Q. Zhao, X.-Z. Chen, Y. Zhou, X.-M. Zhang, X.Y. Xu and W.-C. Yuan, Organic Letters, 2017, 19, 4508-4511.

50 D. Cao, A. Ying, H. Mo, D. Chen, G. Chen, Z. Wang and J. Yang, The Journal of Organic Chemistry, 2018, 83, 12568-12574.

51 J.-R. Zhuo, B.-X. Quan, J.-Q. Zhao, M.-L. Zhang, Y.-Z. Chen, X.-M. Zhang and W.-C. Yuan, Tetrahedron, 2020, 76, 131115. 
52 J.-J. Suo, J. Du, Y.-J. Jiang, D. Chen, C.-H. Ding and X.-L. Hou, Chinese Chemical Letters, 2019, 30, 1512-1514.

53 M. J. Bird, S. M. Wales, C. Richardson and C. J. T. Hyland, Synlett, 2020, 31, 916-924.

54 K. Pasturaud, B. Rkein, M. Sanselme, M. Sebban, S. Lakhdar, M. Durandetti, J. Legros and I. Chataigner, Chem. Commun., 2019, 55, 7494-7497.

55 H. Wang, Q. Hu, M. Wang and C. Guo, iScience, 2020, 23, 100840.

56 H. Huang, Q.-Z. Li, Y.-Q. Liu, H.-J. Leng, P. Xiang, Q.-S. Dai, X.-H. He, W. Huang and J.-L. Li, Org. Chem. Front., 2020, 10.1039.D0Q000868K.

57 S. E. Denmark and A. Thorarensen, Chemical Reviews, 1996, 96, 137-166.

58 I. Chataigner and S. R. Piettre, Org. Lett., 2007, 9, 41594162.

59 H. Gérard and I. Chataigner, J. Org. Chem., 2013, 78, 9233-9242.

60 G. W. Gribble, Current Organic Chemistry, 2005, 9, 14931519.

61 G. W. Gribble, P. E. Alford and T. L. S. Kishbaugh, HETEROCYCLES, 2010, 80, 831.

62 M. Andreini, F. Chapellas, S. Diab, K. Pasturaud, S. R. Piettre, J. Legros and I. Chataigner, Org. Biomol. Chem., 2016, 14, 2833-2839.

63 H. Gérard and I. Chataigner, Chem. Eur. J., 2017, 23, 13711-13717.

64 P. V. Santhini, S. A. Babu, A. Krishnan R, E. Suresh and J. John, Organic Letters, 2017, 19, 2458-2461.

65 P. V. Santhini, A. Krishnan R, S. A. Babu, B. S. Simethy, G. Das, V. K. Praveen, S. Varughese and J. John, The Journal of Organic Chemistry, , DOI:10.1021/acs.joc.7b02039.

66 S. Roy and G. W. Gribble, Tetrahedron Letters, 2007, 48, 1003-1005. 